\title{
Specific interactions of BCL-2 family proteins mediate sensitivity to BH3-mimetics in diffuse large B-cell lymphoma
}

Haematologica 2020

Volume 105(8):2150-2163

\section{Correspondence:}

MEIKE VOGLER

m.vogler@kinderkrebsstiftung-frankfurt.de

Received: February 26, 2019.

Accepted: October 10, 2019.

Pre-published: October 10, 2019.

doi:10.3324/haematol.2019.220525

Check the online version for the most updated information on this article, online supplements, and information on authorship \& disclosures: www. haematologica.org/content/105/8/2150

(C)2020 Ferrata Storti Foundation

Material published in Haematologica is covered by copyright. All rights are reserved to the Ferrata Storti Foundation. Use of published material is allowed under the following terms and conditions:

https://creativecommons.org/licenses/by-nc/4.0/legalcode. Copies of published material are allowed for personal or internal use. Sharing published material for non-commercial purposes is subject to the following conditions:

https://creativecommons.org/licenses/by-nc/4.0/legalcode, sect. 3. Reproducing and sharing published material for commercial purposes is not allowed without permission in writing from the publisher.

\author{
Victoria M. Smith, ${ }^{1,2}$ Anna Dietz, ${ }^{3}$ Kristina Henz, ${ }^{3}$ Daniela Bruecher, ${ }^{3}$ Ross \\ Jackson, ${ }^{1,2}$ Lisa Kowald, ${ }^{3}$ Sjoerd J.L. van Wijk, ${ }^{3}$ Sandrine Jayne,${ }^{1,2}$ Salvador \\ Macip, ${ }^{1}$ Simone Fulda, ${ }^{3,4,5}$ Martin J.S. Dyer ${ }^{1,2}$ and Meike Vogler ${ }^{1,3}$
}

${ }^{1}$ Department of Molecular and Cell Biology, University of Leicester, Leicester, UK; ${ }^{2}$ Ernest and Helen Scott Haematological Research Institute, University of Leicester, Leicester, UK; ${ }^{3}$ Institute for Experimental Cancer Research in Pediatrics, Goethe-University, Frankfurt, Germany; ${ }^{4}$ German Cancer Research Centre (DKFZ), Heidelberg, Germany and ${ }^{5}$ German Cancer Consortium (DKTK), Partner Site Frankfurt, Germany

\section{ABSTRACT}

The BCL-2-specific inhibitor, ABT-199 (venetoclax) has exhibited remarkable clinical activity in nearly all cases of chronic lymphocytic leukemia. In contrast, responses are usually much less in diffuse large B-cell lymphoma (DLBCL), despite high level expression of BCL-2 in over $40 \%$ of cases, indicating that co-expression of related anti-apoptotic BCL-2 family proteins may limit the activity of ABT-199. We have investigated the roles of BCL-2 proteins in DLBCL cells using a panel of specific BCL-2 homology 3 (BH3)-mimetics and identified subgroups of these cells that exhibited marked and specific dependency on either BCL-2, BCL- $\mathrm{X}_{\mathrm{L}}$ or MCL-1 for survival. Dependency was associated with selective sequestration of the pro-apoptotic proteins BIM, BAX and BAK by the specific anti-apoptotic BCL-2 protein which was important for cellular survival. Sensitivity to $\mathrm{BH} 3$-mimetics was independent of genetic alterations involving the BCL-2 family and only partially correlated with protein expression levels. Treatment with ABT-199 displaced BAX and BIM from BCL-2, subsequently leading to BAK activation and apoptosis. In contrast, apoptosis induced by inhibiting BCL- $\mathrm{X}_{\mathrm{L}}$ with $\mathrm{A} 1331852$ was associated with a displacement of both BAX and BAK from BCL- $\mathrm{X}_{\mathrm{L}}$ and occurred independently of BIM. Finally, the MCL-1 inhibitor S63845 induced mainly BAXdependent apoptosis mediated by a displacement of BAK, BIM and NOXA from MCL-1. In conclusion, our study indicates that in DLBCL, the heterogeneous response to $\mathrm{BH} 3$-mimetics is mediated by selective interactions between BAX, BAK and anti-apoptotic BCL-2 proteins.

\section{Introduction}

Deregulated apoptosis is a key hallmark of cancer, and high expression of antiapoptotic proteins is frequently observed in cancer cells. Apoptosis is initiated by ligation of death receptors on the cell surface or by the release of cytochrome $\mathrm{c}$ into the cytosol followed by formation of the apoptosome (intrinsic apoptosis). Among the most important regulators of apoptosis is the BCL-2 protein family, which consists of both pro- and anti-apoptotic proteins. ${ }^{1}$ The pro-apoptotic BCL2 proteins BAX and BAK are essential for the execution of intrinsic apoptosis, as they mediate the release of cytochrome $\mathrm{c}$ from the mitochondrial intermembrane space. The anti-apoptotic proteins (BCL-2, BCL-X $\mathrm{L}_{\mathrm{L}}, \mathrm{MCL}-1, \mathrm{BCL}-\mathrm{w}, \mathrm{BCL} 2 \mathrm{~A} 1$ and $\mathrm{BCL}-\mathrm{B})$ inhibit the activation of $\mathrm{BAX}$ and $\mathrm{BAK}$, thus preventing the release of cytochrome c. BAX and BAK can be bound and inhibited directly by the antiapoptotic BCL-2 proteins; alternatively, their activation can be inhibited by sequestration of BIM or related BCL-2 homology domain 3 (BH3)-only proteins. In this latter model, the release of BH3-only proteins from anti-apoptotic BCL-2 proteins is required in order to allow the BH3-only proteins to interact and directly activate BAX/BAK. 
BCL-2 was identified as the target for the $t(14 ; 18)(q 32.3 ; q 21.3)$ chromosomal translocation involving the BCL2 gene with the immunoglobulin heavy chain transcriptional enhancer in follicular lymphoma and related B-cell malignancies including diffuse large B-cell lymphoma (DLBCL). ${ }^{2}$ This chromosomal translocation results in constitutive expression of BCL-2 and increased resistance to apoptosis. About $40 \%$ of DLBCL display high expression of BCL-2, not only due to $t(14 ; 18)(q 32.3 ; q 21.3)$ but also due to gene copy number alterations and amplifications. ${ }^{3}$ These genetic changes are associated with poor prognosis, particularly when combined with those affecting MYC in double-hit lymphomas. ${ }^{4,5}$ Apart from these genetic changes, BCL2 is also among the most commonly mutated genes in DLBCL, ${ }^{6}$ with $91 / 393$ cases reported as mutated in the COSMIC database (cancer.sanger.ac.uk/cosmic). In comparison, mutations involving MCL-1 (3/391) or BCL-X $(0 / 391)$ are rare in DLBCL. A recent study analyzed the protein expression of BCL-2, BCL- $\mathrm{X}_{\mathrm{L}}$ and MCL-1 in a large set of DLBCL cell lines and patients' tissues and confirmed high expression of these anti-apoptotic proteins. ${ }^{7}$ RNA sequencing data obtained from a large cohort of DLBCL patients $(n=584)$ indicated high expression of all main anti-apoptotic BCL-2 proteins in DLBCL. ${ }^{8}$

Elevated expression of anti-apoptotic BCL-2 proteins in cancer makes these proteins promising targets for the development of novel therapeutics. The first inhibitor for clinical use, ABT-199 (venetoclax), selectively targets BCL-2 and has been approved for the treatment of chronic lymphocytic leukemia and acute myeloid leukemia. ${ }^{9-11}$ Chronic lymphocytic leukemia cells display uniform sensitivity to ABT-199 and clinical responses are observed irrespective of genotype, demonstrating that the most important anti-apoptotic protein in chronic lymphocytic leukemia is BCL-2. ${ }^{12}$

In this study, we hypothesized that other BCL-2 family proteins, such as BCL- $\mathrm{X}_{\mathrm{L}}$ and $\mathrm{MCL}-1$, are important therapeutic targets in DLBCL. Here, for the first time directly comparing specific $\mathrm{BH} 3$-mimetics that target either BCL2 (ABT-199). ${ }^{13}$ BCL-X (A1331852) $^{14}$ or MCL-1 (S63845) ${ }^{15}$ in an extensive panel of DLBCL cell lines and primary cells, we identified subgroups of DLBCL that depended on individual BCL-2 family proteins for survival. Dependency was associated with the presence of preformed complexes of the respective anti-apoptotic BCL2 protein with BIM, BAX and BAK, indicating that sensitive cells were highly primed and that sequestration of BAX/BAK by anti-apoptotic BCL-2 proteins was necessary for cellular survival.

\section{Methods}

\section{Materials}

All chemicals apart from ABT-199, A1331852, A1155463, A1210477 (Selleck Chemicals, Houston, TX, USA), and S63845 (ApexBio, Taiwan) were from Sigma (Deisenhofen, Germany). Most cell lines used in this study were obtained from Deutsche Sammlung von Mikroorganismen und Zellkulturen (DSMZ; Braunschweig, Germany) except Pfeiffer and SUDHL2 cells (American Type Culture Collection; Manassas, VA, USA), OCILY10 (Sandeep Dave, Duke University, Durham, NC, USA), MedB1 ${ }^{16}$ (Peter Moeller, University of Ulm, Ulm, Germany) and Karpas-1106 ${ }^{17}$ (Abraham Karpas, University of Cambridge,
Cambridge, UK). All cell lines were authenticated by short tandem repeat profiling and routinely tested for mycoplasma contamination. Primary patient-derived samples were obtained from patients attending the University Hospital of Leicester, UK. Local ethical approval (Leicestershire, Northamptonshire and Rutland REC06/Q2501/122) and patients' consent were obtained through the Haematological Tissue Bank of the Ernest and Helen Scott Haematological Research Institute, Leicester, UK. Peripheral blood mononuclear cells were isolated from the blood of patients presenting in leukemic phase and the CellTiterGlo assay (Promega, Mannheim, Germany) was used to assess these cells' viability.

\section{Western blotting and immunoprecipitation}

For western blotting, proteins were obtained using Tris-lysis buffer containing $1 \%$ TritonX. Western blotting was performed using the following antibodies: mouse anti-BCL-2 (M088701-2, Dako Agilent, Hamburg, Germany), rabbit anti-BCL-X $\mathrm{X}_{\mathrm{L}}(2762 \mathrm{~S}$, Cell Signaling, Beverly, MA, USA), rabbit anti-MCL-1 (ADIAAP-240F, Enzo, Farmindale, NY, USA), rabbit anti-BIM (3183S, Cell Signaling), mouse anti-NOXA (ALX-804-408, Enzo), rabbit anti-BAK (06-536, Upstate/Merck), mouse anti-BAX (2772S, Cell Signaling) and mouse anti-GAPDH (5G4-6C5, BioTrend, Hy Test Ltd., Turku, Finland). Immunoprecipitation was performed using the following antibodies: hamster anti-BCL-2 551051, BD Bioscience, Heidelberg, Germany), rabbit anti-BCL$\mathrm{X}_{\mathrm{L}}$ (ab32370, Abcam), rabbit anti-MCL-1 (ADI-AAP-240F, Enzo), mouse anti-BAX (610983, BD Bioscience), and rabbit anti-BAK (ab32371, Abcam). Antibodies were crosslinked to protein G dynabeads (Invitrogen, Karlsruhe, Germany). CHAPS containing lysates were incubated overnight at $4^{\circ} \mathrm{C}$ with the antibody-protein $G$ complexes before the precipitates were washed in lysis buffer and analyzed by western blotting

\section{BH3-profiling}

Cells were gently permeabilized with $0.0025 \%$ digitonin before exposure to $0.1,1$ or $10 \mu \mathrm{M}$ of synthetic peptides (BIM, $\left.\mathrm{BAD}, \mathrm{XXa1} \mathrm{Y}_{4} \mathrm{eK}^{18}\right)$. Loss of mitochondrial membrane potential was measured using $1 \mu \mathrm{M}$ JC-1 via a Hidex Sense plate reader as described previously. ${ }^{19}$ Results were normalized to those of dimethylsulfoxide (DMSO) and carbonyl cyanide-4-(trifluoromethoxy)phenylhydrazone (FCCP) controls.

\section{Genetic modifications}

For silencing of individual genes, cells were electroporated with a neon transfection system (ThermoFisher) using two pulses of $20 \mathrm{~ms}$ at $1200 \mathrm{~V}$. The following silencer select short interfering (si)RNA (ThermoFisher) were used at $100 \mathrm{nM}$ : BAX (\#1s1888, \#3s1890), BAK (\#1s1880, \#2s1881), BIM (\#1s195011, \#2s195012, \#3s223065), BCL-X (s1921), MCL-1 (s8583), and NOXA (s10709, s10710). CRISPR/Cas9 engineering was done as described previously. ${ }^{20}$ Briefly, three guide (g)RNA against human BAK (GGTAGACGTGTAGGGCCAGA, TCACCTGCTAGGTTGCAG, AAGACCCTTACCAGAAGCAG) or against green fluorescent protein as a non-human target (NHT) (GGAGCGCACCATCTTCTTCA, GCCACAAGTTCAGCGTGTC, GGGCGAGGAGCTGTTCACCG) were cloned in pLentiCRISPRv2 (Addgene \# 52961). Lentiviral particles were generated by co-transfecting pLenti-CRISPRv2 NHT and BAK with pPAX2 (Addgene \# 12260) and pMD2.G (Addgene \# 12259) in HEK293T cells and used to transduce U2946 or SUDHL8 target cells using spin transduction followed by puromycin selection and isolation of BAK-deleted single clones using limited dilution. The BAK expression status was assessed using western blotting. 


\section{Results}

\section{BCL-2, BCL- $X_{L}$ and MCL-1 are important therapeutic} targets in diffuse large B-cell lymphoma

To investigate the roles of the main anti-apoptotic BCL2 proteins in DLBCL, we assessed the effects of selective BH3-mimetics in DLBCL cells. We focused on commercially available inhibitors that target BCL-2 (ABT-199),

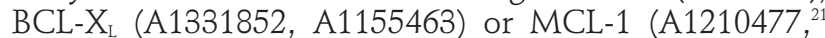
S63845). Primary cells isolated from patients' tissues were exposed to different concentrations of BH3-mimetics before analysis of cell viability using a CellTiterGlo Assay (Figure 1A). The direct comparison of ABT-199, A1331852 and S63845 revealed that the response to BH3mimetics was highly heterogeneous, with three of seven samples (\#1, \#2, and \#3) responding to low nanomolar concentrations of $\mathbf{6 6 3 8 4 5}$, sample \#4 responding best to
ABT-199, and samples \#5, \#6 and \#7 being more resistant to all three BH3-mimetics. Notably, sample \#3 displayed a better response to A1331852 than to ABT-199, indicating that although none of these primary samples displayed the highest sensitivity to A1331852, all three main anti-apoptotic BCL-2 proteins may be relevant therapeutic targets in DLBCL.

As primary patient-derived DLBCL cells are limited and freshly isolated malignant $B$ cells rapidly lose viability ex vivo, we continued our investigations in a panel of 18 DLBCL cell lines comprising the main subtypes of DLBCL defined by gene expression profiling. ${ }^{22}$ namely activated B-cell, germinal center and primary mediastinal B-cell lymphoma-like cells (Table 1). In addition, based on their mutation/translocation signature derived from public databases, we characterized the cell lines according to their genetic drivers into MCD (MYD88 and CD796
A
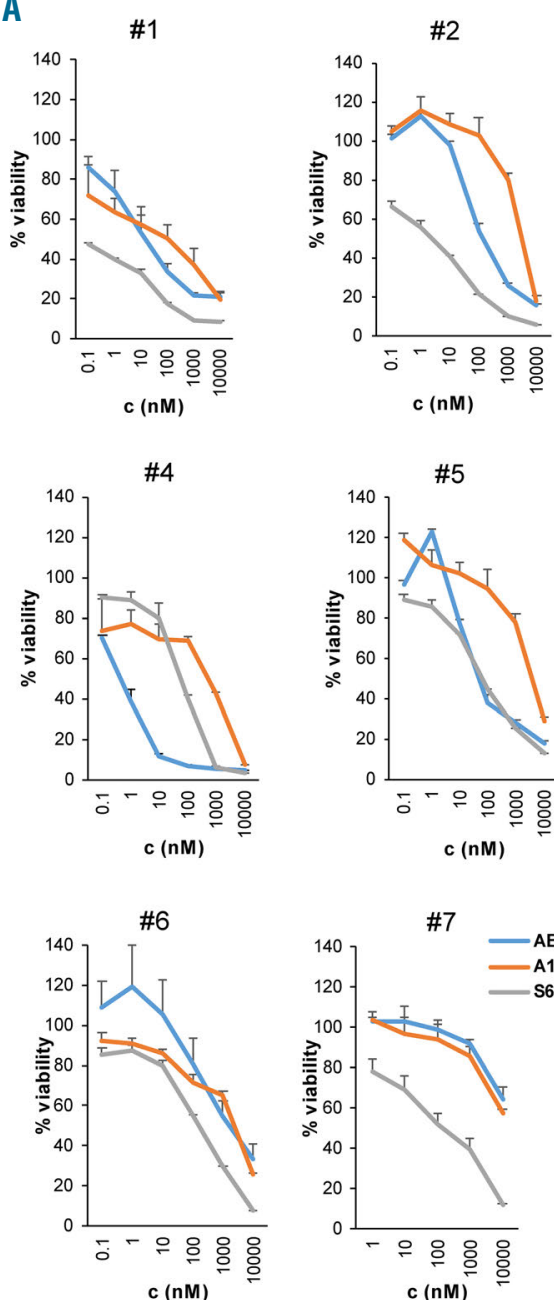

$\mathbf{c}(\mathbf{n M})$
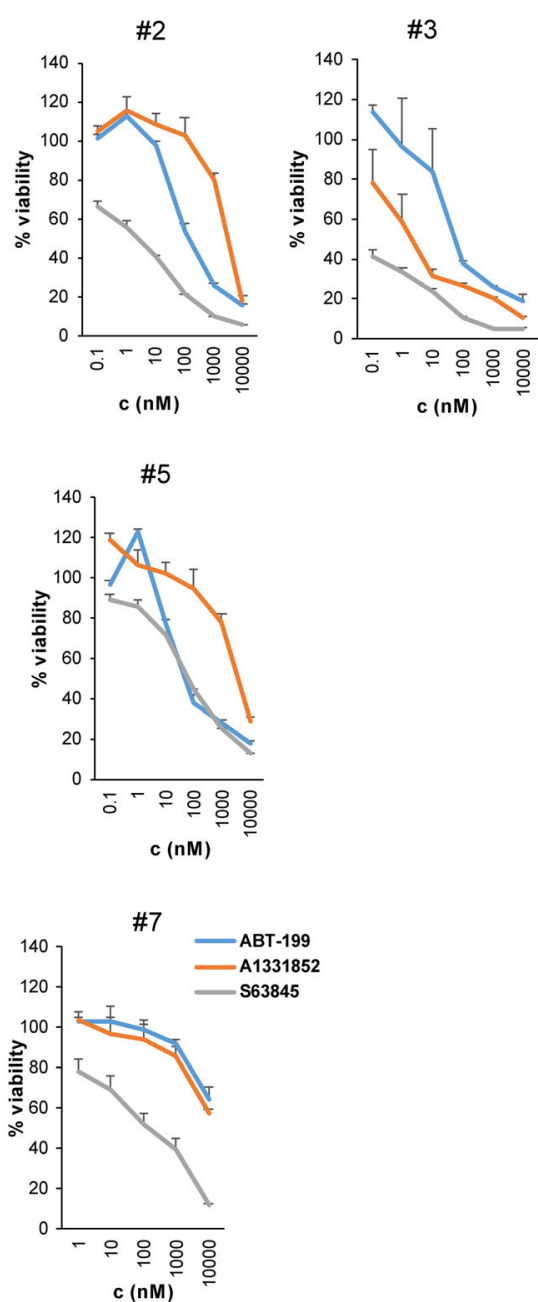

B
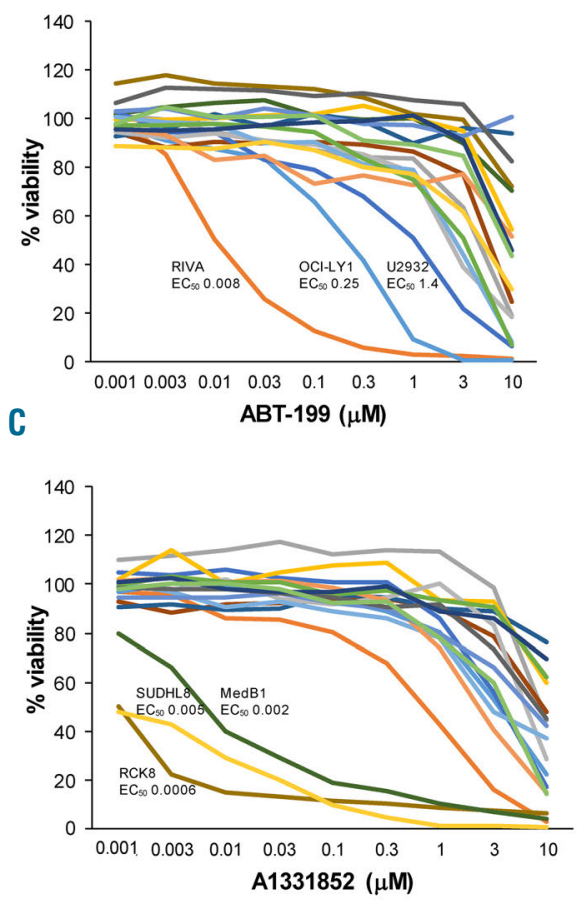

D

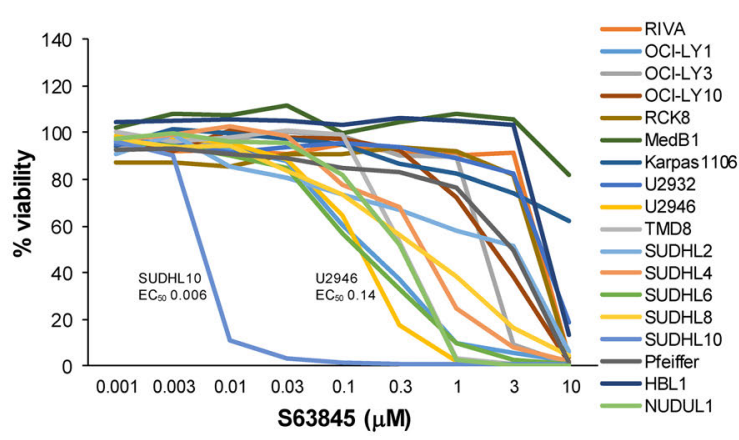

Figure 1. Diffuse large B-cell lymphoma cells display a heterogeneous sensitivity to selective BH3-mimetics. (A) Primary cells isolated from patients' tissues were incubated with different concentrations of ABT-199, A1331852 or S63845 for 24 h before analysis of cell viability using CellTiterGlo. Experiments were performed in triplicate and data shown are the mean and standard deviation (SD) for each individual sample $(n=7)$. (B-D) Diffuse large B-cell lymphoma cell lines were exposed to different concentrations of ABT-199 (B), A1331852 (C) or S63845 (D) before analysis of cell viability using CellTiterGlo at $72 \mathrm{~h}$. Data shown are the mean and $\mathrm{SD}(\mathrm{n}=4-6)$. Half maximal effective concentration $\left(\mathrm{EC}_{50}\right.$ ) values, as displayed in Table 1, are indicated for highly sensitive cell lines. 


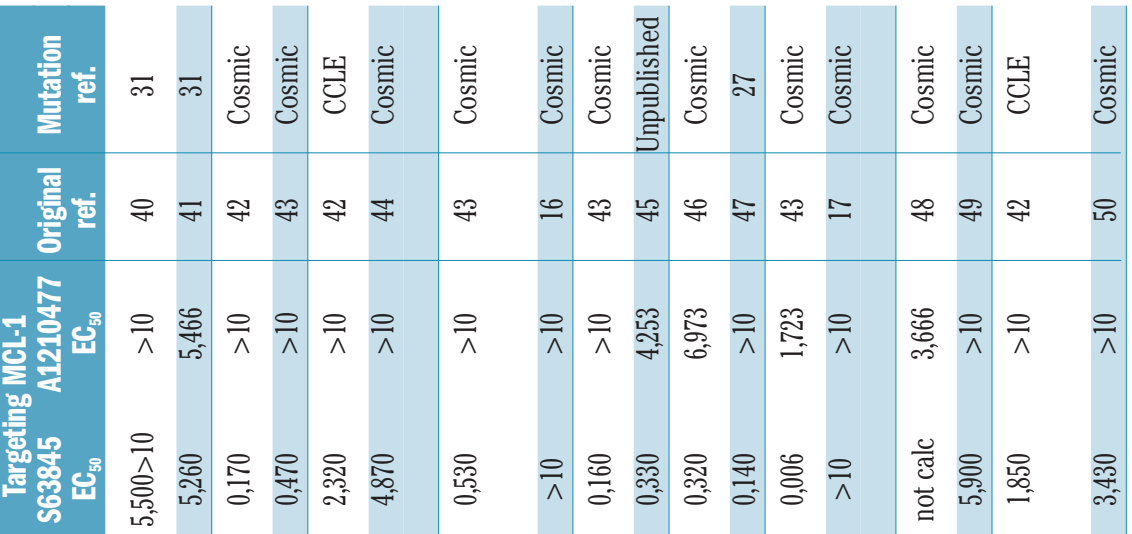

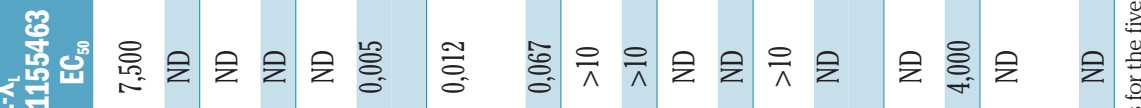

層

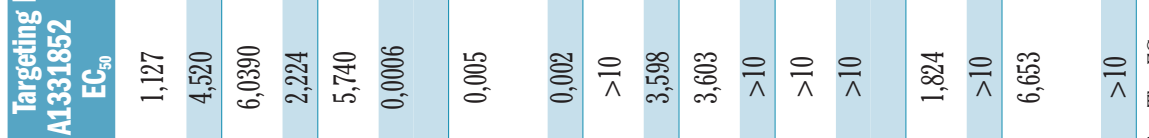

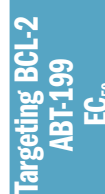

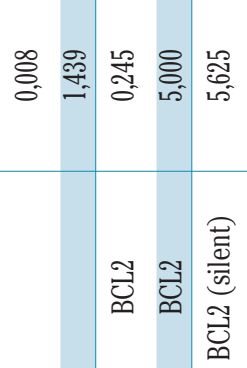

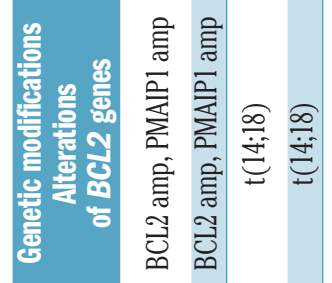

产高

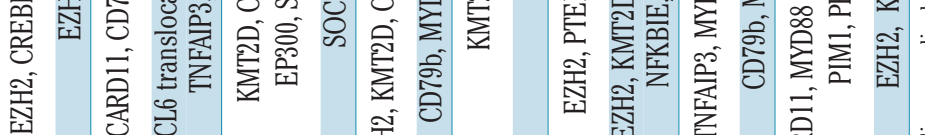

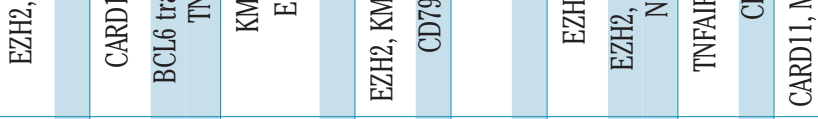

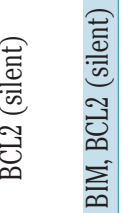

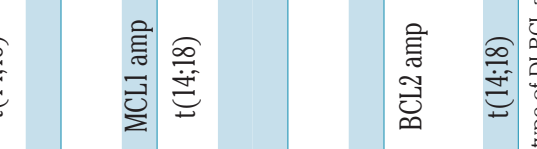

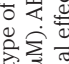

急界

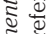
竞

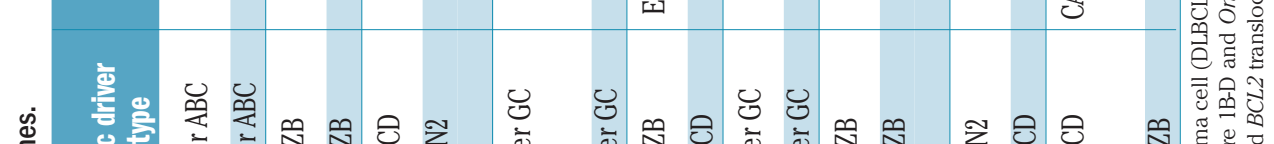

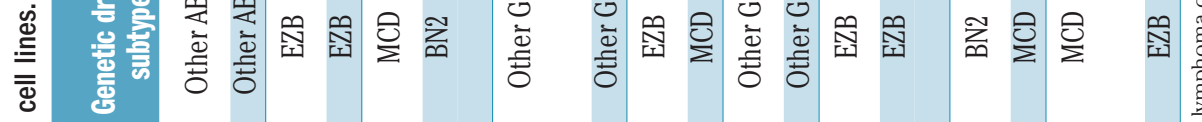

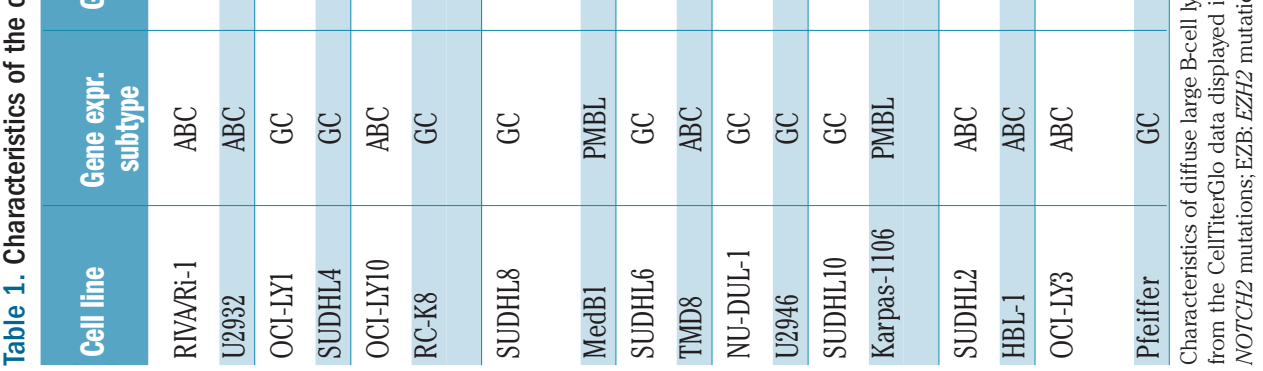


mutations), BN2 (BCL6 fusion and NOTCH2 mutations), $\mathrm{N} 1$ (NOTCH1 mutations) and EZB (EZH2 mutations and $B C L 2$ translocations) as recently described. ${ }^{8}$ An initial comparison of different selective $\mathrm{BH} 3$-mimetics indicated that A1331852 was more potent than A1155463, and S63845 displayed significantly higher potency than A1210477 (Figure 1B-D, Online Supplementary Figure S1, Table 1).

DLBCL cell lines displayed highly heterogeneous responses to BH3-mimetics (Figure 1B-D). RIVA, U2932 and OCI-LY1 cells responded primarily to ABT-199, indicating a dependency on BCL-2 for survival. In contrast, RCK8, SUDHL8 and MedB1 cells were highly sensitive to A1331852, demonstrating BCL- $\mathrm{X}_{\mathrm{L}}$ dependency. Notably, these three cell lines displayed sensitivity to low nanomolar/picomolar concentrations of A1331852, with half maximal effective conentrations $\left(E_{50}\right)$ of $0.0006,0.005$ and $0.002 \mu \mathrm{M}$, respectively, highlighting its potency in cellular systems. Susceptibility to S63845 was more homogeneous than that to ABT-199 or A1331852, with ten of the 18 cell lines responding to less than $3 \mu \mathrm{M}$. The most sensitive cell line in our panel was SUDHL10 (EC $\mathrm{E}_{50}$ $0.006 \mu \mathrm{M}$ ), which was previously described to be resistant to BH3-mimetics. ${ }^{23}$

Most cell lines were primarily sensitive to one specific BH3-mimetic, indicating firstly that in each cell line one particular BCL-2 family protein was functionally most dominant and, secondly and unexpectedly, that expression of the other anti-apoptotic BCL- 2 proteins could not prevent induction of apoptosis. However, four cell lines (OCI-LY1, RIVA, SUDHL8 and TMD8) were sensitive to multiple inhibitors. Notably, five of the 18 cell lines did not respond to any inhibitor at submicromolar concentrations (OCI-LY10, Pfeiffer, OCI-LY3, Karpas-1106 and HBL1) (Table 1).

\section{BH3-profiling using XXa1_Y4eK may predict sensitivity to $\mathrm{A} 1331852$}

To confirm that BCL- $\mathrm{X}_{\mathrm{L}}$ and MCL-1 are important therapeutic targets in DLBCL, we utilized a genetic approach to silence BCL-X $\mathrm{X}_{\mathrm{L}}$ or MCL-1. Knockdown of BCL-X $\mathrm{X}_{\mathrm{L}}$ by siRNA was sufficient to induce apoptosis in RCK8, SUDHL8 and MedB1 cells but not in the BCL-2-dependent RIVA or U2932 cells, whereas knockdown of MCL1 was sufficient to induce apoptosis in SUDHL10, TMD8 and U2946 cells but not in BCL-X $\mathrm{X}_{\mathrm{L}}$-dependent MedB1 cells, which correlated with susceptibility to A1331852 and S63845, respectively (Figure 2A-D). BH3-profiling may serve as a surrogate assay to investigate priming in tumor samples. ${ }^{24}$ To examine whether BH3-profiling may predict the sensitivity to $\mathrm{BH} 3$-mimetics in DLBCL, permeabilized cells were exposed to $\mathrm{BH} 3$-peptides from BIM, which binds to all anti-apoptotic BCL-2 proteins, BAD, which binds to BCL-2 and BCL- $X_{L}$, and the engineered peptide XXa1_Y $4 \mathrm{eK}$, which binds with high affinity selectively to BCL- $\mathrm{X}_{\mathrm{L}}{ }^{18}$ All tested cell lines displayed a dose-dependency towards BIM (Figure 2E). Both RIVA and RCK8 cells also responded to BAD and XXa1_Y4eK, congruent with a dependency on BCL-2 and/or BCL- $\mathrm{X}_{\mathrm{L}}$ for survival. In contrast, the MCL-1-dependent cell line SUDHL10 did not respond to BAD or XXa1_Y4eK, as observed in previous studies. ${ }^{23}$ Next, we asked whether the response to XXa1_Y $4 \mathrm{eK}$ may correlate with the sensitivity to A1331852 in a larger panel of cell lines. The $\mathrm{EC}_{50}$ for A1331852 displayed a significant correlation with the response to $\mathrm{XXa1} Y 4 \mathrm{eK}(P<0.001)$, indicating that $\mathrm{BH} 3$-profiling could serve as a biomarker to predict responses to $\mathrm{BH} 3$-mimetics provided that specific and potent peptides, such as XXa1_Y4eK, are available (Figure $2 \mathrm{~F})$.

\section{BCL-2 protein expression was highly variable but only partially associated with sensitivity to BH3-mimetics}

Next, we aimed to understand the heterogeneity in the response to BH3-mimetics in the panel of DLBCL cell lines. Western blot analysis revealed that the expression of BCL-2 proteins was highly variable (Figure $2 \mathrm{G}$, Online Supplementary Figure S2A). Several of the cell lines have genetic alterations involving BCL2 e.g. $\mathrm{t}(14 ; 18)$ (q32.3; 21.3$)$ chromosomal translocation or gene amplifications (Table 1). Quantification of protein expression indicated that gene alterations of BCL2 correlated partially with high protein expression (Online Supplementary Figure S2B). Although there was a tendency for cells with genetic alterations of $B C L 2$ to be more sensitive to ABT-199, as reported previously, ${ }^{25}$ this difference was not statistically significant (Online Supplementary Figure S2C). Of note, although SUDHL4 and SUDHL6 cells are reported to contain missense mutations of $B C L 2$, which may prevent antibody recognition. ${ }^{26} \mathrm{BCL}-2$ protein expression was detectable with the antibody used in our study.

The highest expression of BCL- $\mathrm{X}_{\mathrm{L}}$ was detected in RCK8, SUDHL8 and MedB1 cells, which were most sensitive to A1331852. Expression of MCL-1 was more homogeneous, with all cell lines expressing detectable MCL-1 protein and the highest expression being in the MCL1 amplified U2946 cells. ${ }^{27}$ The pore-forming BCL-2 proteins BAK and BAX were expressed in all cell lines while BH3-only protein expression was highly variable (Figure 2G).

To test whether susceptibility to BH3-mimetics was associated with the levels of expression of their targeted BCL-2 proteins, the $\mathrm{EC}_{50}$ values were correlated with BCL-2 protein expression. Linear regression analysis showed a significant correlation between the response to ABT-199 and expression of BCL-2, but this appeared to be driven by the very high or very low BCL-2-expressing cell lines. Sensitivity to ABT-199 also correlated significantly with the ratio of BCL-2 to MCL-1 expression (Online Supplementary Figure S3A). Although the cell lines with highest sensitivity to A1331852 expressed BCL-X strongly, the correlation of $\mathrm{BCL}-\mathrm{X}_{\mathrm{L}}$ expression and sensitivity to A1331852 was not statistically significant, which may be explained by several cell lines expressing BCL- $X_{\mathrm{L}}$ strongly but nevertheless being resistant to A1331852 (HBL1, Pfeiffer and Karpas-1106). Susceptibility to A1331852 was more strongly correlated with the ratio of $\mathrm{BCL}-\mathrm{X}_{\mathrm{L}}$ expression to a combined expression of the other anti-apoptotic proteins BCL- 2 and MCL-1, although the resistant Pfeiffer and Karpas-1106 cells still displayed a high ratio and made this correlation weak $\left(\mathrm{R}^{2}=0.23\right)$ (Online Supplementary Figure S3B). Sensitivity to S63845 did not correlate with expression of its target MCL-1 (Online Supplementary Figure S3C) but, as described previously, ${ }^{15}$ did to some extent inversely correlate with expression of $\mathrm{BCL}-\mathrm{X}_{\mathrm{L}}$. In addition, we found a significant correlation of S63845 sensitivity with the ratio of MCL-1 to BIM expression. 
A

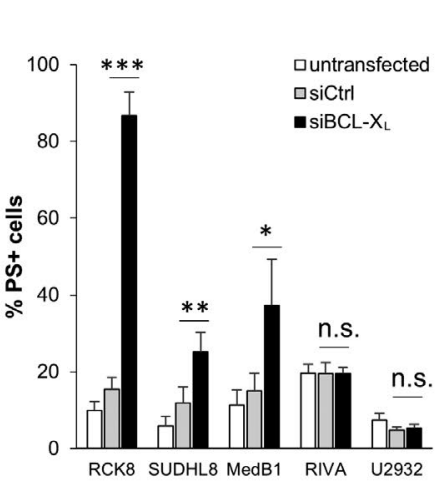

D

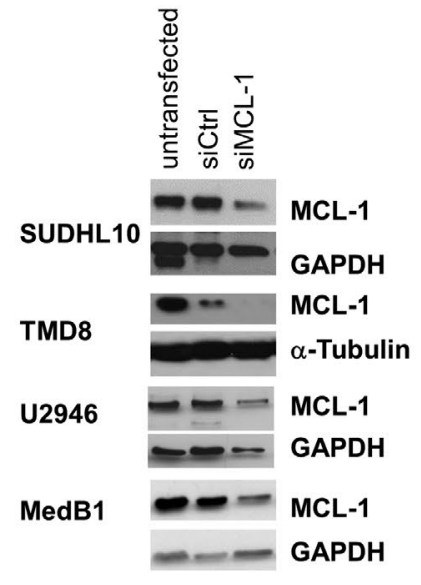

B

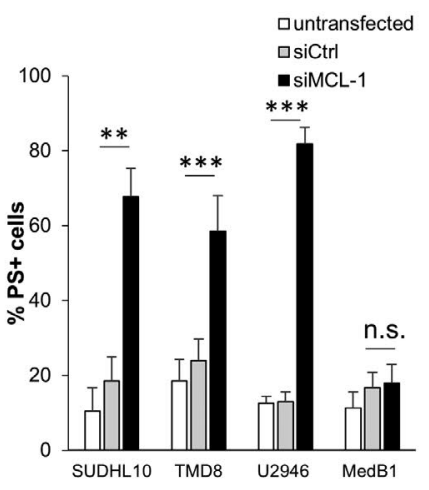

C

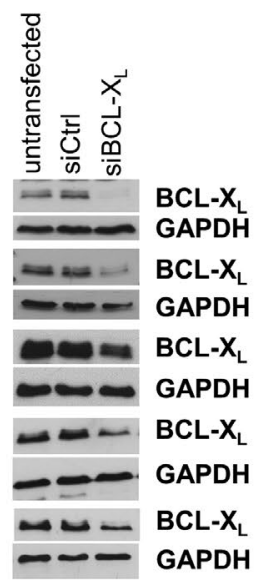

E

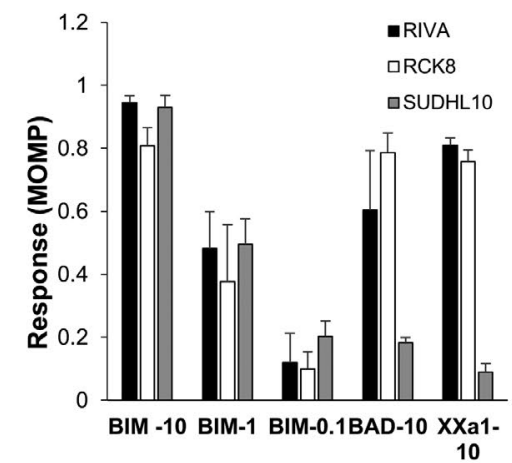

$\mathbf{F}$

G

$\begin{array}{cccc}\text { mainly } & \text { mainly } & \text { mainly } & \\ B C L-2 & B C L-X_{L} & \text { MCL-1 } & \text { resistant } \\ \text { dependent } & \text { dependent dependent } & \end{array}$

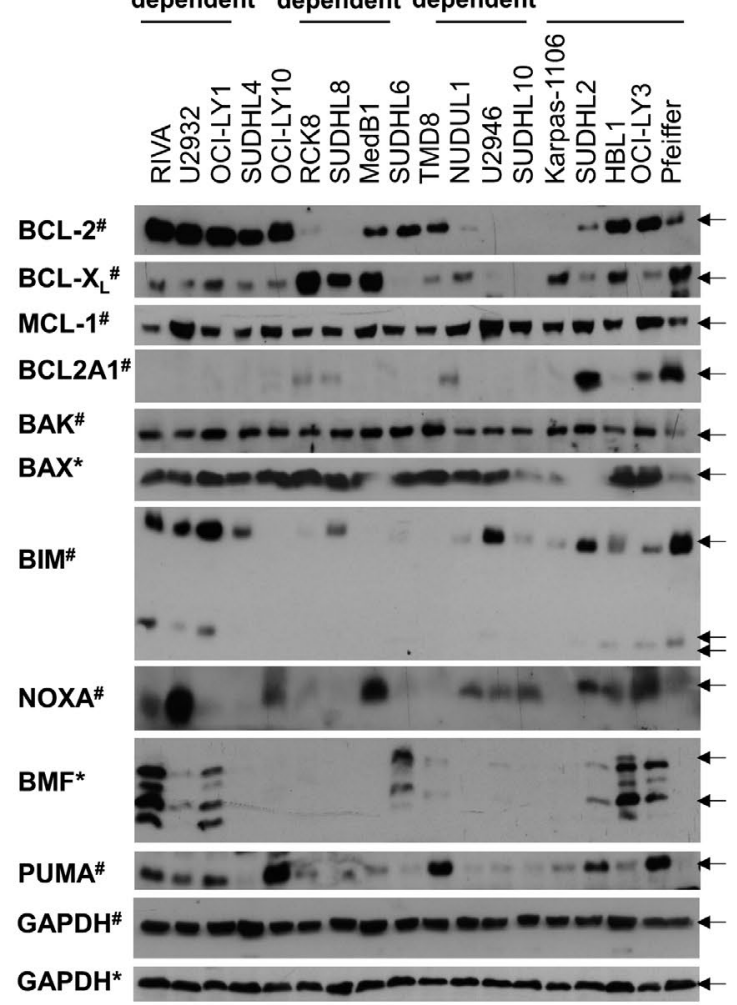

Figure 2. BH3-profiling and genetic silencing of BCL- $\mathrm{X}_{\mathrm{L}}$ and MCL-1 confirms that these proteins are important therapeutic targets independent of protein expression. (A-D) The importance of the anti-apoptotic proteins BCL- $X_{L}(A, C)$ and MCL-1 $(B, D)$ in diffuse large $B$-cell lymphoma (DLBCL) was confirmed using short interfering (si)RNA-mediated knockdown. (A) Apoptosis was investigated $48 \mathrm{~h}$ after siRNA-mediated knockdown of BCL-X $X_{L}$. Data shown are the mean and standard deviation (SD) $(n=3)$. (B) Apoptosis was investigated $24 \mathrm{~h}$ after siRNA-mediated knockdown of MCL-1. Data shown are the mean and SD $(n=3)$. (C, D) Representative western blots showing knockdown efficiency are displayed for $B C L-X_{L}(C)$ and MCL-1 (D). GAPDH or $\alpha$-tubulin was used as a loading control. $(E, F)$ BH3-profiling was performed using selected cell lines and exposure of permeabilized cells to BIM $(10,1$ or $0.1 \mu \mathrm{M})$, BAD $(10 \mu \mathrm{M})$ or XXa1_Y4eK $(10 \mu \mathrm{M})$ peptides before staining with $\mathrm{JC}-1$ and fluorescence reading over time. Data shown are the mean and SD $(n=4-5)$. (F) The response to XXa1_Y4eK was correlated with the half maximal effective concentration $\left(\mathrm{EC}_{50}\right)$ for $\mathrm{A} 1331852$. Cell lines corresponding to the data points are indicated. (G) Expression of BCL-2 proteins in DLBCL cells was analyzed by western blotting. As this was done on two independent gels (*, ") two GAPDH loading controls are shown. A representative example of five independent experiments is shown. Quantification is shown in Online Supplementary Figure S2A. 
Sensitivity to BH3-mimetics correlated with sequestration of pro-apoptotic BCL-2 proteins

To interrogate whether the interactions of anti- and pro-apoptotic BCL-2 proteins might influence susceptibility to BH3-mimetics, we selected ten representative cell lines and performed immunoprecipitation of the main anti-apoptotic proteins (Figure 3). In the BCL-2-dependent cell lines (RIVA, U2932 and OCI-LY1), BIM was highly bound to BCL-2, with no detectable binding of BIM to BCL- $\mathrm{X}_{\mathrm{L}}$ or MCL-1, despite high protein expression of BCL-X and MCL-1. In contrast, BIM was highly bound by MCL-1 in the MCL-1-dependent cell lines SUDHL10 and U2946. These two cell lines expressed low levels of BCL-2 and BCL- $\mathrm{X}_{\mathrm{L}}$, which may explain why BIM was bound to MCL-1. In the BCL- $\mathrm{X}_{\mathrm{L}}$-dependent SUDHL8 and RCK8 cells, BIM expression was comparatively low, and some BIM appeared bound to BCL- $\mathrm{X}_{\mathrm{L}}$ but not to BCL-2 or MCL-1. Collectively, these data suggest a relationship between the sequestration of BIM by the different antiapoptotic BCL-2 proteins and a dependency on the respective anti-apoptotic BCL-2 protein for survival. However, the resistant cells OCI-LY3 and Pfeiffer, which did not respond to any $\mathrm{BH} 3$-mimetic, also displayed binding of BIM to BCL-2 and/or BCL-X $\mathrm{X}_{\mathrm{L}}$ and MCL-1. Pfeiffer cells have been reported to contain a missense mutation in BIM (S10C), but this mutation did not prevent binding of BIM to its anti-apoptotic binding partners. In line with its published binding profile, ${ }^{28}$ the $\mathrm{BH}$-only protein NOXA was exclusively bound by MCL-1 but not by BCL2 or BCL- $X_{\mathrm{L}}$ in all cell lines.

Besides binding $\mathrm{BH} 3$-only proteins, the anti-apoptotic BCL-2 proteins can also sequester BAX and BAK. ${ }^{29}$ Intriguingly, we found that both BAX and BAK are bound by the anti-apoptotic BCL-2 proteins, highlighting that in DLBCL the anti-apoptotic BCL-2 proteins may act by inhibiting already partially activated BAX and BAK, in which the BH3-domain is exposed and accessible for interaction with the anti-apoptotic BCL-2 proteins. ${ }^{30}$ Thus, BAX was sequestered by BCL-2 predominantly in the BCL-2-dependent cell lines, and predominantly sequestered by BCL- $\mathrm{X}_{\mathrm{L}}$ in the BCL- $\mathrm{X}_{\mathrm{L}}$-dependent cell lines, indicating that the binding of BAX by the respective anti-apoptotic BCL-2 protein was associated with sensitivity to specific inhibitors (Figure 3). Besides BAX, BAK was also bound by BCL- $\mathrm{X}_{\mathrm{L}}$ in the BCL- $\mathrm{X}_{\mathrm{L}}$-dependent cell lines and by MCL-1 in the MCL-1-dependent cell lines. Taken together, our investigations show that sensitive DLBCL cell lines were highly primed and that direct sequestration of BAX and BAK by the anti-apoptotic BCL-2 proteins could be the last step preventing apoptosis in these cells.

\section{BH3-mimetics induced cell death by displacing and activating $B A X$ and $B A K$}

Next, we asked how BH3-mimetics induced cell death in DLBCL cell lines. Exposure to BH3-mimetics induced caspase-3 cleavage, caspase-dependent phosphatidylserine externalization and loss of mitochondrial membrane potential (Online Supplementary Figure S4). The activation and oligomerization of BAX and/or BAK are key events in the intrinsic apoptotic pathway and require conformational changes. Treatment with BH3-mimetics induced conformational changes associated with activation and oligomerization of BAX and BAK in all sensitive cell lines (Online Supplementary Figure S5A-C). Of note, some active BAK was detectable in untreated cells, but the amount of constitutively active BAK did not correlate with sensitivity (Online Supplementary Figure S5D).

To investigate how $\mathrm{BH} 3$-mimetics induced the activation of BAX and BAK we interrogated how the interac-

\section{Lysate / Input}

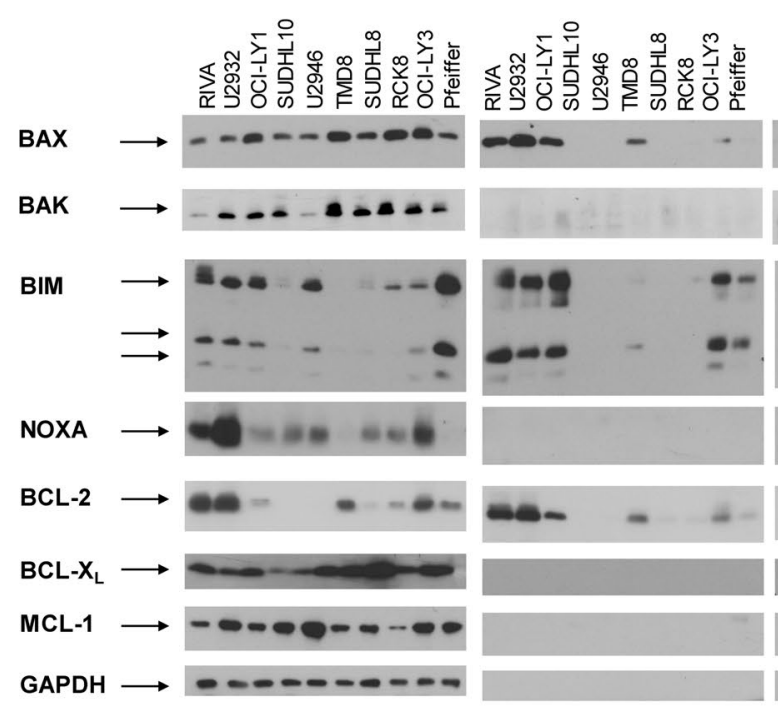

IP BCL-X

IP MCL-1

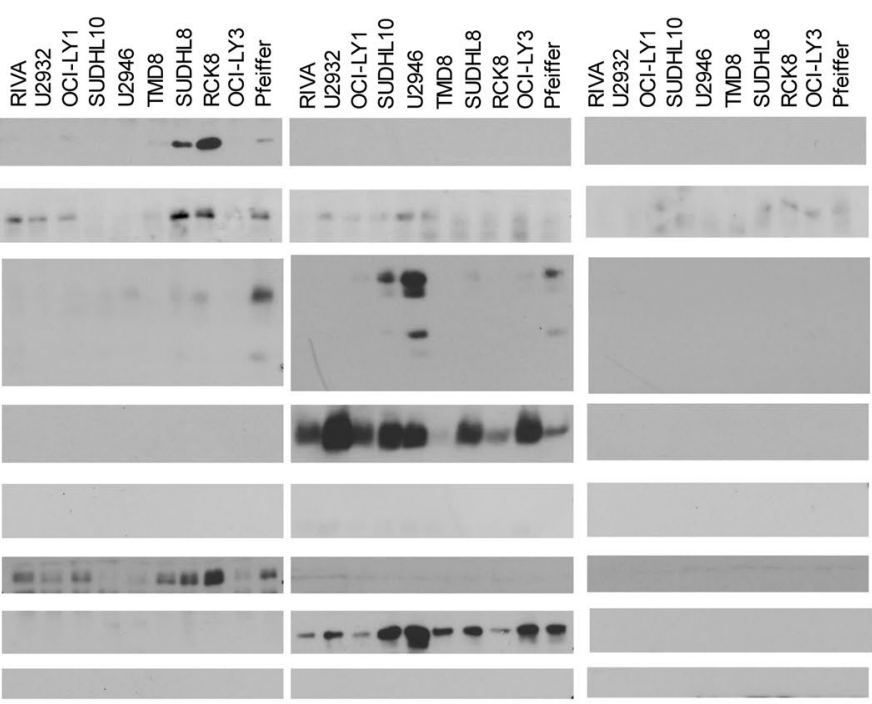

Figure 3. Priming correlates with sensitivity to BH3-mimetics. The interaction of anti- and pro-apoptotic BCL-2 proteins was investigated in a selection of ten cell lines with varying sensitivities to BH3-mimetics. Immunoprecipitation of BCL-2, BCL- $\mathrm{X}_{\mathrm{L}}$ and $\mathrm{MCL}-1$ was performed in untreated cell lysates followed by analysis of binding of pro-apoptotic BCL-2 proteins (BIM, NOXA, BAX and BAK) using Western blotting. Protein G beads without primary antibody were used to control for unspecific binding. Staining with BCL-2, BCL- $X_{L}, M C L-1$ and GAPDH was performed to demonstrate efficient immunoprecipitation and equal protein loading, respectively. Representative western blots of two independent experiments are shown. 
tion of pro- and anti-apoptotic proteins changed upon exposure to BH3-mimetics (Figure 4). In the BCL-2dependent cell lines RIVA and U2932, the recently described displacement of BIM from BCL- $2^{31}$ was difficult to detect but some reduction in binding of BIM to BCL-2 was found in U2932 cells. In RIVA cells, a minor amount of BIM appeared bound to BCL- $\mathrm{X}_{\mathrm{L}}$ following treatment with ABT-199, which may indicate a low level of BIM displacement from BCL-2. In both cell lines, less BAX was bound to BCL-2 following treatment with ABT-199, indicating a direct displacement of BAX from BCL-2 (Figure 4A). Similarly, in the BCL- $\mathrm{X}_{\mathrm{L}}$-dependent cell lines, BIM binding to $\mathrm{BCL}-\mathrm{X}_{\mathrm{L}}$ was reduced upon treatment with A1331852. Strikingly, both BAX and BAK were less bound by BCL- $\mathrm{X}_{\mathrm{L}}$ upon $\mathrm{A} 1331852$ treatment, supporting the hypothesis that $\mathrm{BH} 3$-mimetics can directly displace BAX and BAK (Figure 4B). Treatment with S63845 in the

A

RIVA

U2932

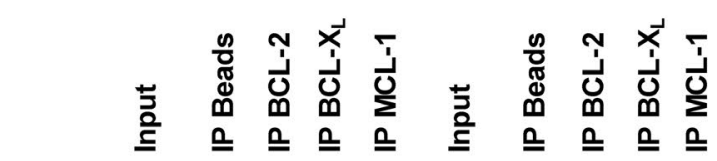

ABT-199 $\overline{-+}+\overline{-+} \overline{-++}+\overline{-+}-\overline{-+}-\overline{+}$
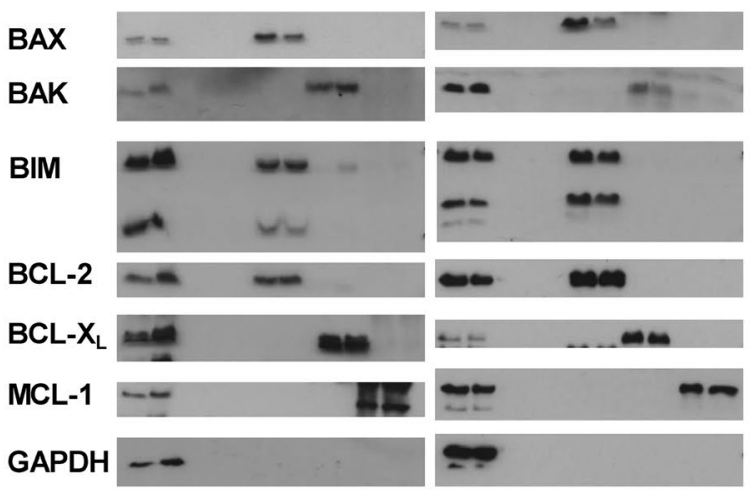

C

SUDHL10

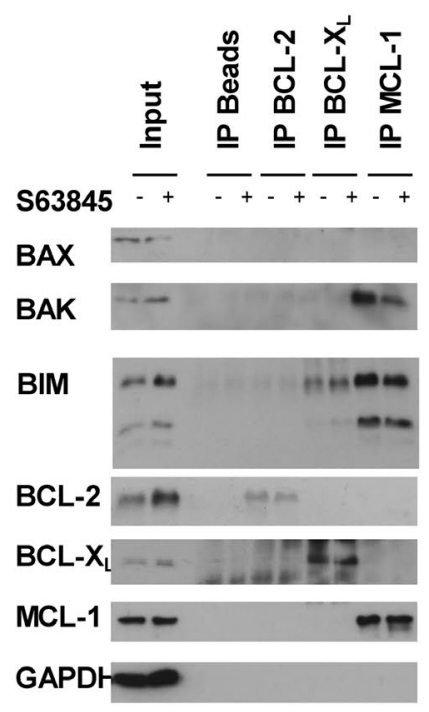

MCL-1-dependent cell lines resulted in less binding of BIM and BAK to MCL-1 (Figure 4C). In summary, these studies demonstrate that treatment with $\mathrm{BH}$-mimetics resulted in reduced binding of pro-apoptotic BCL-2 proteins.

The displacement of BIM could be functionally important for apoptosis induction, as released BIM could initiate apoptosis by binding directly to BAX and BAK and activating them. To investigate whether BIM is necessary, we performed siRNA-mediated knockdown of BIM followed by treatment with BH3-mimetics. Combined use of two distinct siRNA partially inhibited BH3-mimetic induced cell death in a treatment- and cell-line-dependent manner, as BIM knockdown reduced cell death in RIVA, SUDHL10 and to a lesser extent in U2946 cells (Figure 5A-C, Online Supplementary Figure S6), although efficient knockdown was achieved in all cell lines (Figure 5D). As

B

$\mathrm{RCK8}$

SUDHL8

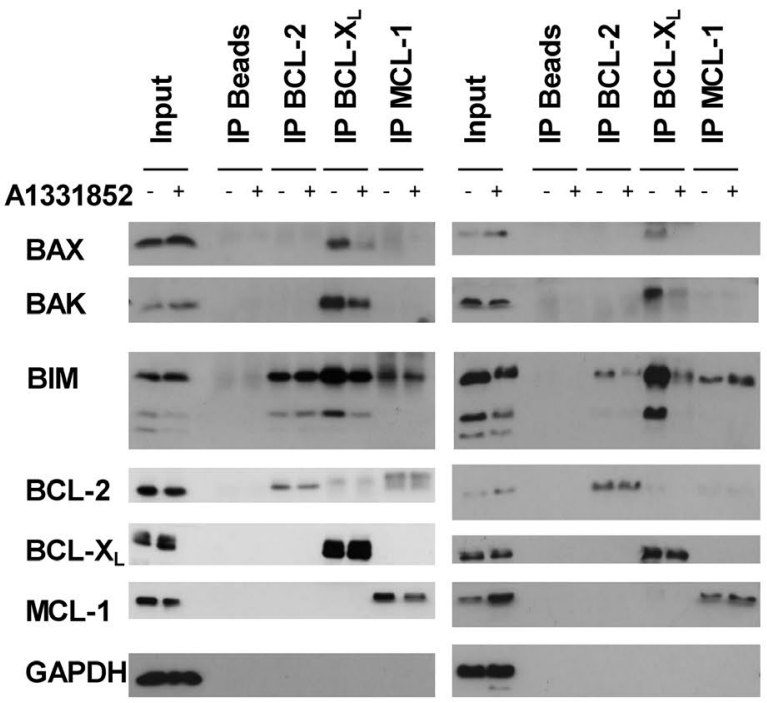

Figure 4. On-target binding of BH3-mimetics displaces pro-apoptotic BCL-2 proteins. (A-C) The interaction of anti- and pro-apoptotic $B C L-2$ proteins (BIM, BAX and BAK) was studied upon treatment with the BH3-mimetics (A) ABT-199 (RIVA, $3 \mathrm{nM}$ and U2932, $10 \mathrm{nM}$ ), (B) A1331852 (RCK8, $3 \mathrm{nM}$ and SUDHL8, $10 \mathrm{nM}$ ) or (C) S63845 (SUDHL10, $100 \mathrm{nM}$ and U2946, $300 \mathrm{nM}$ ) for $4 \mathrm{~h}$. In order to exclude downstream caspase-mediated effects on protein expression, the broad range caspase inhibitor zVAD.fmk was added to the cells. Input lanes show the presence of overall protein in the lysate, and immunoprecipitation (IP) lanes show interaction with $\mathrm{BCL}-2, \mathrm{BCL}-\mathrm{X}_{\mathrm{L}}$ or $\mathrm{MCL}-1$. Protein $\mathrm{G}$ beads without primary antibody were used to control for unspecific binding. Staining with BCL-2, BCL-X, MCL-1 and GAPDH was performed to demonstrate efficient immunoprecipitation and equal protein loading, respectively. Representative western blots of two to five independent experiments are shown. 
A

RIVA

ABT-199

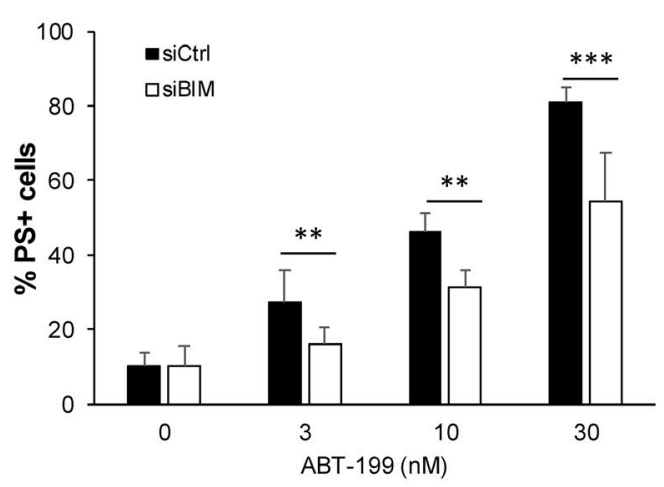

U2932

ABT-199

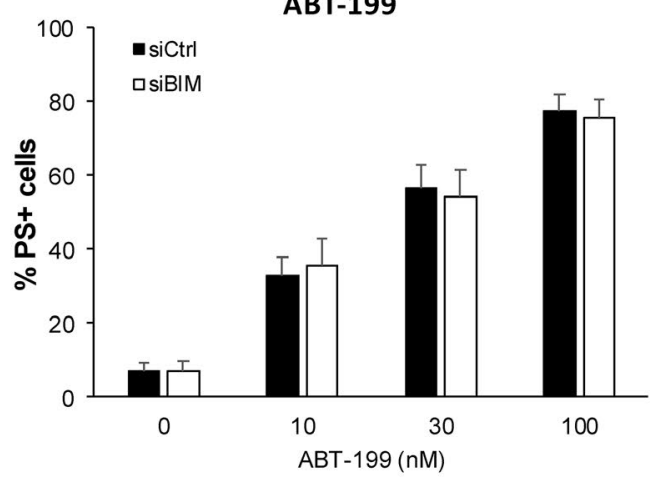

C

SUDHL10

S63845

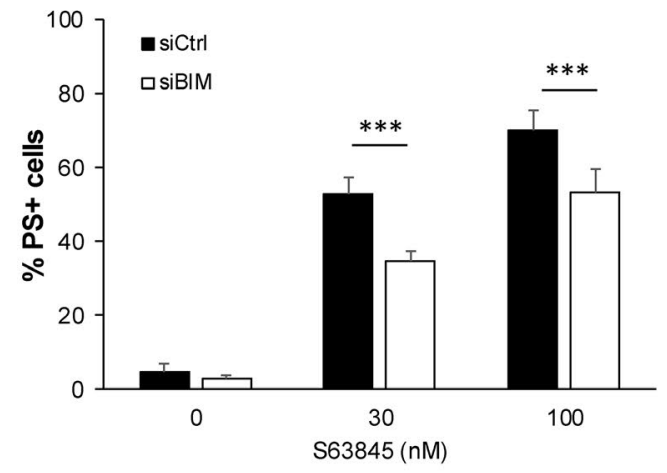

J2946

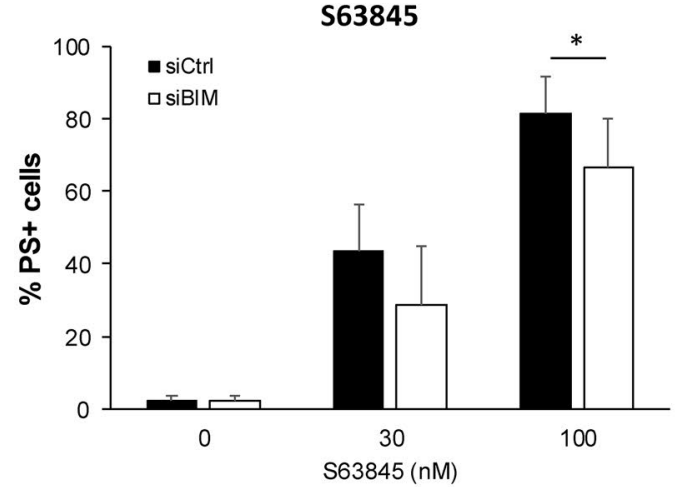

B

RCK8

A1331852

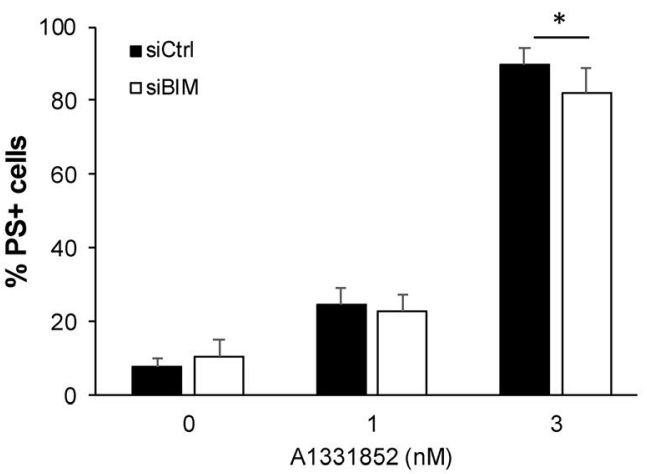

SUDHL8

A1331852

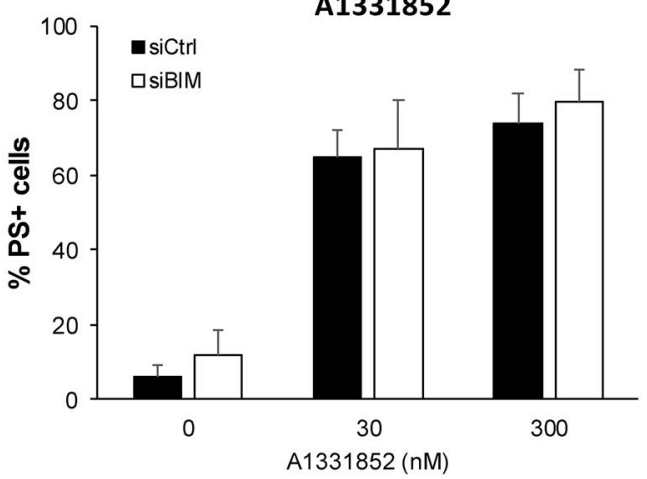

D

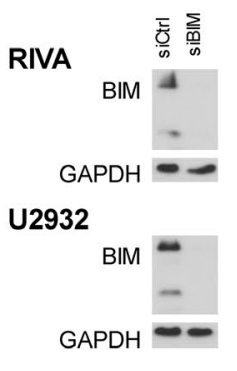

RCK8

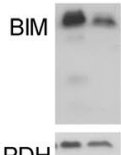

SUDHL8

BIM

GAPDH - -

SUDHL10

BIM

$\mathrm{GAPDH}=-$

U2946

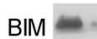

GAPDH - -
Figure 5. BH3-mimetic-induced cell death is partially dependent on BIM. (A-C) Depletion of BIM was achieved using a combination of two distinct shortinterfering (si)RNA oligonucleotides (siBIM\#1 and siBIM\#2). Data on individual BIM siRNA are provided in Online Supplementary Figure S6. Upon transfection, cells were treated with the indicated concentrations of ABT-199 (A) in RIVA or U2932 cells, upon treatment with A1331852 (B) in RCK8 or SUDHL8 cells, or upon treatment with $\mathrm{S} 63845$ (C) in SUDHL10 or U2946 cells for 4 or $6 \mathrm{~h}$ and phosphatidylserine (PS) exposure was analyzed by staining with annexin V-FITC and flow cytometry. Non-targeting siRNA (siCtrl) was used as a control. The mean and standard deviation are shown $(n=3-4)$. (D). Knockdown efficiency was controlled by western blotting $48 \mathrm{~h}$ after transfection. $* P<0.05 ; * * P<0.01$; $* * * P<0.001$. 
A
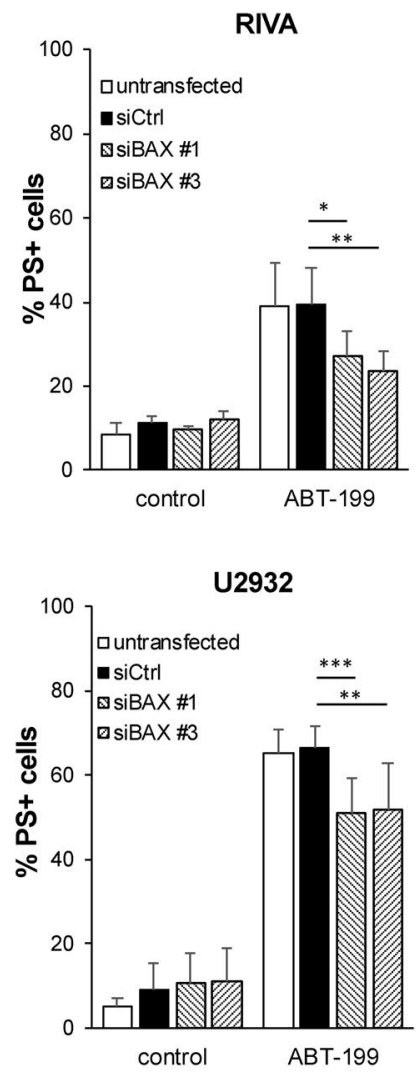

D

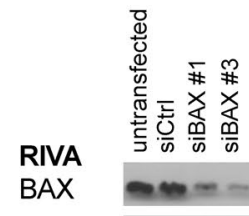

GAPDH $=$

U2932

BAX -

RCK8

BAX

GAPDH

SUDHL8

$\mathrm{BAX}=-$

GAPDH $=-2$

SUDHL10

$\mathrm{BAX}$ -

GAPDH - -

U2946

$\mathrm{BAX}$

GAPDH $=-=$

B

C
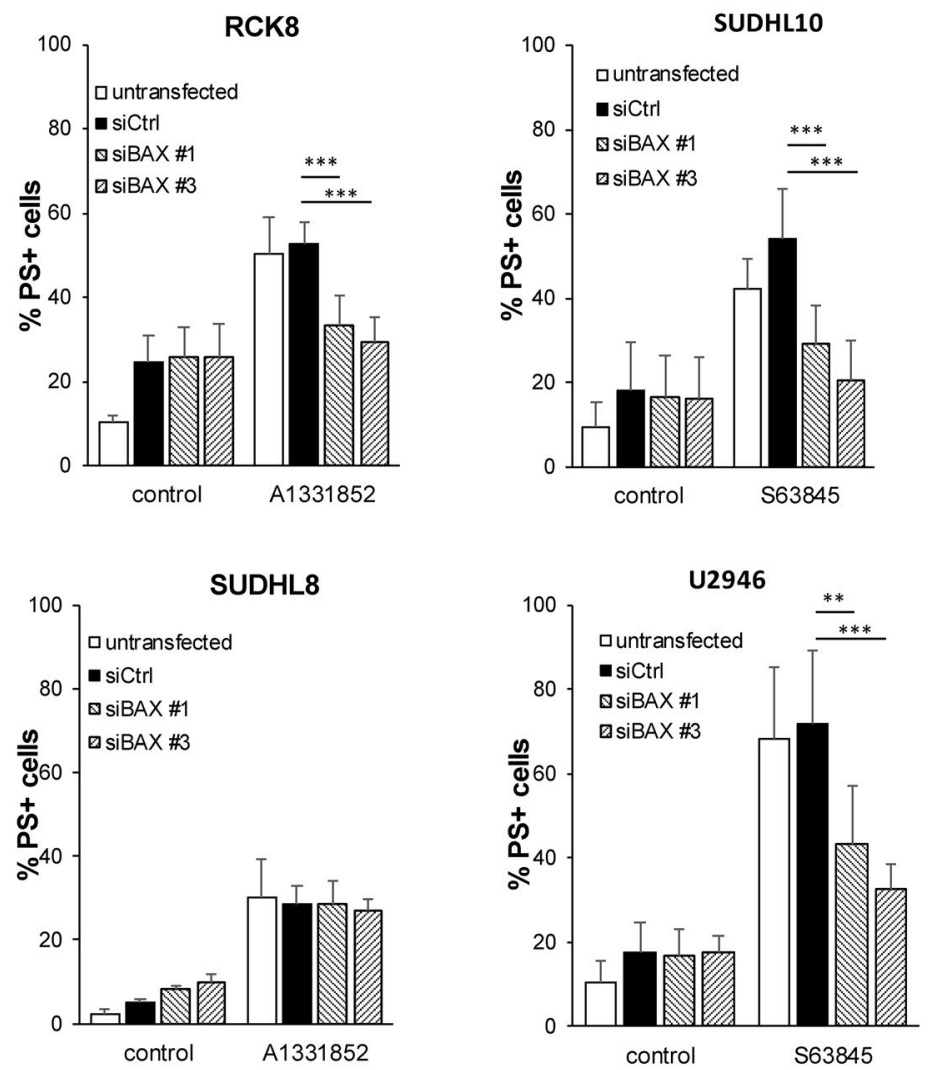

E
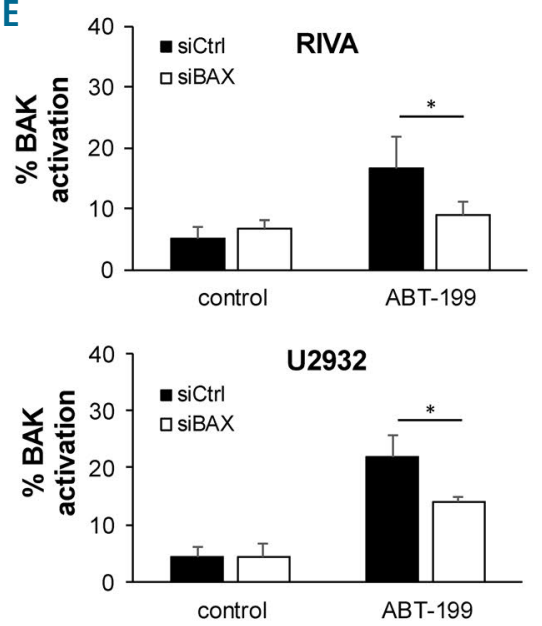

F

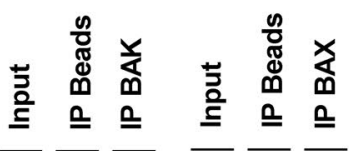

RIVA

BAX

BAK

GAPDH

U2932

BAX

BAK

GAPDH
Figure 6. BH3-mimetic-induced cell death is mediated by BAX. (A-D) Knockdown of BAX using short-interfering (si)RNA-mediated gene silencing was performed before treatment with ABT-199 (A) in RIVA (3 nM) or U2932 (10 nM) cells, upon treatment with $\mathrm{A} 1331852$ (B) in RCK8 (3 nM) or SUDHL8 (10 nM) cells, and upon treatment with $\mathrm{S} 63845$ (C) in SUDHL10 (100 nM) or U2946 (300 $\mathrm{nM}$ ) cells for $4 \mathrm{~h}$ and phosphatidylserine (PS) exposure was analyzed by staining with annexin V-FITC and flow cytometry. Untransfected cells and non-targeting siRNA (siCtrl) were used as controls. The mean and standard deviation (SD) are shown ( $n=3-4)$. (D) Knockdown efficiency was assessed by western blotting. (E) Knockdown of BAX with siRNA constructs \#1 and \#3 combined was followed by treatment with ABT-199 in RIVA $(10 \mathrm{nM})$ or U2932 (30 nM) cells for $4 \mathrm{~h}$ and analysis of BAK activation by flow cytometry. The mean and SD are shown ( $n=3$ for RIVA and $n=2$ for U2932). (F) The interaction between BAK and BAX was assessed by immunoprecipitation (IP) in RIVA or U2932 cells with or without treatment with ABT-199 (+;-). Input lanes show the presence of overall protein in the lysate, and IP lanes show the interaction between BAX and BAK upon treatment with ABT-199. Protein $G$ beads without primary antibody were used to control for unspecific binding. *indicates IgG band. GAPDH was used as a loading control. $* P<0.05 ; * * P<0.01 ; * * * P<0.001$. 
RIVA cells also expressed high levels of the BH3-only protein BMF we asked whether BMF could be functionally important, but silencing of BMF did not affect ABT-199induced apoptosis (Online Supplementary Figure S7).

\section{BAX and BAK were required to mediate ABT-199-induced apoptosis}

Next, we explored the role of BAX in BH3-mimeticinduced cell death. Silencing of BAX using siRNA indicated that BAX was essential for the cell death induced by BH3-mimetics, as cell death was significantly reduced in RIVA, U2932, RCK8, SUDHL10 and U2946 cells (Figure 6A-D). In contrast, knockdown of BAK only reduced apoptosis upon treatment with ABT-199 but not upon treatment with A1331852 or S63845, highlighting a prominent role for BAK only in ABT-199-induced apoptosis (Online Supplementary Figure S8).

We also investigated how BAK was involved in ABT199-induced apoptosis. As no direct inhibition of BAK by BCL-2 was observed, we hypothesized that BAX inhibition by BCL-2 is the initial target of ABT-199, and that once BAX is released, BAK is also activated and accelerates cell death. To test this hypothesis, the activation of BAK was assessed upon silencing of BAX and treatment with ABT-199. In both RIVA and U2932 cells, silencing of BAX resulted in significantly less active BAK induced by ABT-199, suggesting that BAX contributed to activation of BAK (Figure $6 \mathrm{E}$ ). To investigate whether BAX could directly activate $B A K$, the interaction between $B A K$ and BAX was investigated. Treatment with ABT-199 induced complex formation between BAX and BAK in both RIVA and U2932 cells (Figure 6F).

\section{BAX rather than BAK is functionally required for A1331852- or S63845-induced apoptosis}

To exclude that the absence of an influence of BAK silencing on A1331852- or S63845-induced apoptosis may be caused by insufficient knockdown, we performed genetic deletion of BAK using CRISPR/Cas9. Deletion of BAK in SUDHL8 cells had only a minor effect on A1331852-induced cell death as compared to cells transduced with NHT control gRNA (Online Supplementary Figure S9A, B). To investigate whether BAX could be activated in the absence of $\mathrm{BAK}, \mathrm{BAX}$ activation was quantified upon treatment with A1331852 using a conformation-specific antibody and flow cytometry. Although the deletion of BAK had a minor influence on the activation of BAX, BAX could clearly still be activated even though BAK was deleted (Online Supplementary Figure S9C).

To interrogate the role of BAK in S63845-induced apoptosis, BAK was deleted in U2946 cells. In contrast to the data obtained by siRNA-mediated knockdown, genetic deletion of BAK had a significant influence on S63845induced apoptosis in all BAK-deleted clones investigated (Figure 7A). However, S63845-induced apoptosis was not completely inhibited, suggesting that BAX may play a prominent role also upon S63845 treatment. To confirm that S63845-mediated apoptosis involved BAX, knockdown of BAX was performed in BAK-deleted cells (Figure $7 B)$. Knockdown of BAX by siRNA had a stronger influence than BAK deletion on S63845-induced apoptosis. Combined deletion of BAK and depletion of BAX resulted in complete inhibition of S63845-induced apoptosis (Figure 7C). To investigate how BAX may be activated upon inhibition of MCL-1, we first asked whether BAK was essential in activating BAX. Analysis of BAX activation in BAK-deleted cells indicated that BAK may be involved in activating BAX, as BAX activation was significantly reduced in BAK-deleted cells. However, some active BAX was still present in BAK-deleted cells, indicating that other factors may be involved in activating BAX. To explore a role of the BH3-only proteins BIM and NOXA, siRNA-mediated knockdown of BIM and NOXA was performed in BAK-deleted cells. In line with the minor reduction of S63845-induced apoptosis by BIM knockdown (Figure 5C), BIM knockdown also reduced S63845-induced apoptosis in NHT- or BAK-deleted U2946 cells (Figure 7E, F). In addition to BIM, NOXA may also be involved in S63845-induced cell death, as knockdown of NOXA partially reduced S63845-induced apoptosis (Figure 7G,H). These data indicate that NOXA may participate in activating BAX upon S63845 treatment. To explore how NOXA may activate BAK we next investigated the binding of NOXA to MCL-1 and observed a prominent displacement of NOXA from MCL-1 by S63845 (Figure 7I). Taken together, these data indicate that BH3-only proteins displaced from MCL-1 by S63845 may contribute to an activation of BAX which primarily mediates S63845-induced apoptosis.

\section{Discussion}

By investigating the response to selective $\mathrm{BH}$-mimetics we have identified subgroups of DLBCL cells that depend on either BCL-2, BCL-X $\mathrm{X}_{\mathrm{L}}$ or MCL-1 for survival. Our side-by-side comparison of selective BH3-mimetics targeting the main anti-apoptotic proteins suggests that BCL-2, BCL- $X_{\mathrm{L}}$ and MCL-1 are all important therapeutic targets in DLBCL. However, we have not investigated the role of other BCL-2 family proteins, such as BCL2A1 or BCLw, due to the lack of specific inhibitors.

In line with previous studies, our data indicate a correlation of ABT-199 sensitivity with high BCL-2 protein expression. ${ }^{7}{ }^{75}$ However, in our study sensitivity to ABT199 was independent of genetic alterations of BCL-2 and not all cells expressing high BCL-2 levels were sensitive to ABT-199, highlighting the need to better understand the mechanisms of resistance in cells with high expression of BCL-2, such as HBL1 and OCI-LY3. Although RIVA and U2932 also expressed high levels of BCL-X $\mathrm{X}_{\mathrm{L}}$ and MCL-1, BAX and BIM were exclusively sequestered by BCL-2, indicating that in these cells BCL-2 is the preferred binding partner for the pro-apoptotic proteins. The molecular basis for this preferential binding is not known. Increased binding to BCL-2 instead of the related protein BCL- $\mathrm{X}_{\mathrm{L}}$ cannot be explained by different binding affinities, as BIM BH3-peptides bind more strongly to BCL- $\mathrm{X}_{\mathrm{L}}$ than to BCL-2, ${ }^{28,32}$ but may be explained by the amount of accessible protein at the mitochondria or by enhanced protein stability. ${ }^{33}$ Our data indicate that ABT-199 released proapoptotic BAX and BIM and that the released BAX induced activation of BAK, as knockdown of BAX significantly reduced BAK activation (Figure $6 \mathrm{E}$ ). The involvement of BIM in ABT-199-induced apoptosis appears to be cell-type-dependent, as BIM knockdown reduced apoptosis in RIVA but not in U2932 cells (Figure 5).

In contrast, in the BCL- $\mathrm{X}_{\mathrm{L}}$-dependent cell lines RCK8 and SUDHL8, BAX and BAK were exclusively bound to $B C L-X_{\mathrm{L}}$. These cell lines expressed high levels of BCL- $\mathrm{X}_{\mathrm{L}}$ 
but low levels of BCL-2 and MCL-1, which may explain why $\mathrm{BCL}-\mathrm{X}_{\mathrm{L}}$ was the preferred binding partner. Treatment with A1331852 displaced both BAX, BAK and BIM from BCL- $X_{L}$. Knockdown experiments indicated that although BIM was displaced, it did not contribute to A1331852-induced apoptosis, whereas both BAX and
BAK were involved. Taken together, these experiments indicate that the marked sensitivity of RCK8 and SUDHL8 cells reflected the high levels of BAX and BAK bound by BCL- $\mathrm{X}_{\mathrm{L}}$ and that the displacement of these proteins by A1331852 was sufficient to induce apoptosis. Another study has shown a requirement for BH3-only
A

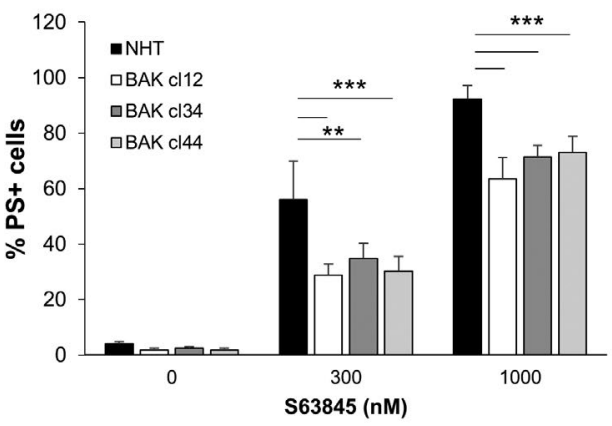

D

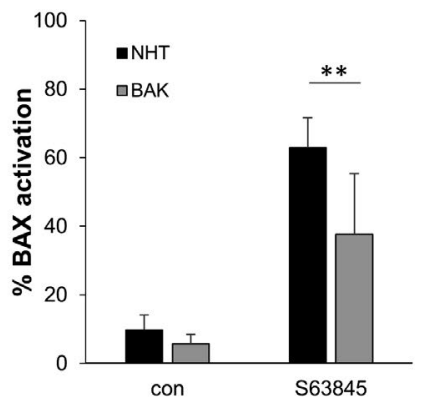

B

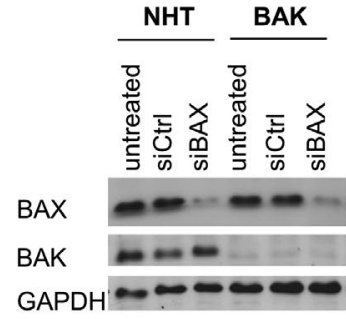

E

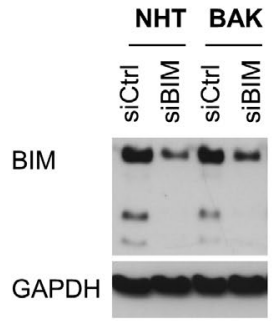

C

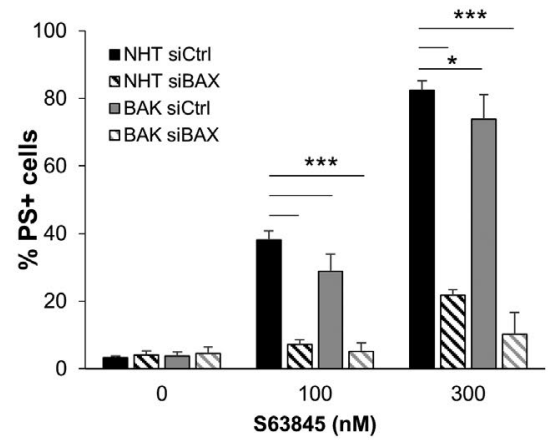

F
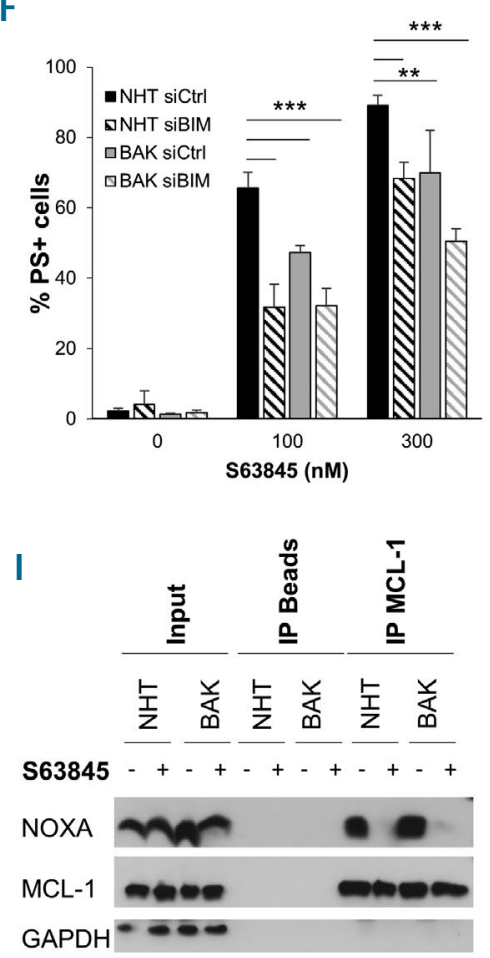

G

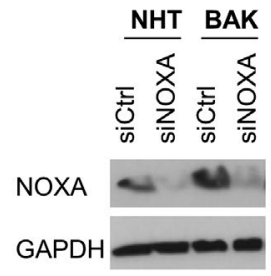

H

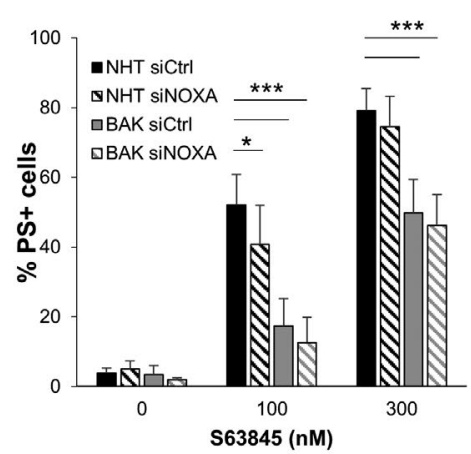

Figure 7. S63845 induced apoptosis is mainly independent of BAK. (A) BAK was deleted from U2946 cells using CRISPR/Cas9. Cells were transduced with pLentiCRISPRv2 either carrying non-human target (NHT) control guide (g)RNA or BAK gRNA (BAK) followed by selection of stable clones with BAK deletion. NHT or BAK-deleted clones were exposed to different concentrations of S63845 for $4 \mathrm{~h}$ before analysis of phosphatidylserine (PS) exposure by staining with annexin V-FITC and flow cytometry. The mean and standard deviation (SD) are shown ( $n=3)$. (B. C) To achieve efficient knockdown, BAX was silenced in U2946 NHT control or BAKdeleted cells (clone 12) using siRNA\#1 and \#3 combined. (B) Knockdown of BAX and genetic deletion of BAK was confirmed by western blotting. (C) Cells were exposed to different concentrations of S63845 for $4 \mathrm{~h}$ before analysis of PS exposure by staining with annexin V-FITC and flow cytometry. The mean and SD are shown $(n=4)$. (D) NHT or BAK-deleted cells were treated with $100 \mathrm{nM} \mathrm{S63845}$ for $4 \mathrm{~h}$ before analysis of BAX activation using intracellular staining with an active conformation-specific BAX antibody and flow cytometry. The mean and SD are shown ( $n=3)$. (E, F) BIM was silenced using short-interfering (si)RNA in U2946 NHT control or BAK-deleted cells (clone 12). (E) Knockdown of BIM was confirmed by Western blotting. (F) Cells were exposed to different concentrations of S63845 for $4 \mathrm{~h}$ before analysis of PS exposure by staining with annexin V-FITC and flow cytometry. The mean and SD are shown ( $n=4)$. (G, H) NOXA was silenced using siRNA in U2946 NHT control or BAK-deleted cells (clone 12). (G) Knockdown of NOXA was confirmed by western blotting. (H) Cells were exposed to different concentrations of S63845 for $4 \mathrm{~h}$ before analysis of PS exposure by staining with annexin V-FITC and flow cytometry. The mean and SD are shown ( $\mathrm{n}=4)$. (I) NHT or BAK-deleted clones were exposed to $\mathbf{S 6 3 8 4 5}(100 \mathrm{nM})$ for $4 \mathrm{~h}$ before lysis in CHAPS-containing buffer and immunoprecipitation (IP) of MCL-1. The interaction with NOXA is demonstrated by western blotting. Input lanes showing the presence of overall protein in the lysate, and IP lanes show the interaction with MCL-1. Protein G beads without primary antibody were used to control for unspecific binding. A representative blot of two independent experiments is shown. ${ }^{*} P<0.05 ; * \star P<0.01 ; * * * P<0.001$. 
proteins for A1331852-induced apoptosis in HCT-116 cells ${ }^{34}$ highlighting important differences from DLBCL.

In terms of S63845-induced apoptosis, the MCL-1dependent cell lines SUDHL10 and U2946 did not express especially high levels of MCL-1, but both cell lines expressed only small amounts of BCL-2 and BCL-X $\mathrm{X}_{\mathrm{L}}$. BIM and BAK were predominantly sequestered by MCL-1 in these cells. BAK has previously been identified as an essential mediator of S63845-induced cell death in breast cancer cells, ${ }^{35}$ but our data demonstrate that BAX may be more important for MCL-1 inhibition in DLBCL. Thereby, BAK and/or BH3-only proteins displaced from MCL-1 contributed to the activation of BAX and apoptosis. Besides BIM, our data also indicate that NOXA is a potential mediator of S63845-induced apoptosis. NOXA is highly bound by MCL-1 and displaced by S63845, which may enable NOXA to act as a direct activator for BAX, as suggested previously. ${ }^{36,37}$

Taken together, our study demonstrates that the sensitivity to BH3-mimetics is underlined by sequestration of BIM, BAX and/or BAK by the anti-apoptotic BCL-2 proteins, a phenomenon that is disrupted by $\mathrm{BH} 3$-mimetics, leading to predominantly BAX-mediated apoptosis. Therefore, our data support a model in which the major function of the anti-apoptotic BCL-2 proteins in DLBCL cells is to directly sequester or inhibit BAX. Dependent on the abundance of the different anti-apoptotic BCL-2 proteins, the pro-apoptotic proteins preferentially bind to either BCL-2, BCL-X $\mathrm{X}_{\mathrm{L}}$ or MCL-1 which renders these cells highly sensitive to selective $\mathrm{BH}$-mimetics. However, our data also highlight that besides BCL-2, BCL- $\mathrm{X}_{\mathrm{L}}$ or MCL-1 additional anti-apoptotic BCL-2 proteins such as BCL2 $\mathrm{A}^{38}$ and $\mathrm{BCL}-\mathrm{w}^{39}$ may play important roles in DLBCL, as some cell lines, including Pfeiffer and OCILY3, display high priming but are nevertheless not responsive to inhibition of $\mathrm{BCL}-2, \mathrm{BCL}-\mathrm{X}_{\mathrm{L}}$ or MCL-1. A more detailed understanding of the molecular mechanisms of resistance in these cell is required to enable the best use of potent BCL-2 family inhibitors in clinical practice.

\section{Acknowledgments}

The authors would like to thank C. Hugenberg for expert secretarial assistance and Sandeep Dave for providing us with OCI-LY10 cells. This work was partially supported by the Else Kröner-Fresenius-Stiftung (to MV), the Experimental Cancer Medicine Center Leicester and funding from the Scott Waudby Trust (to SJ and MJSD).

\section{References}

1. Adams JM, Cory S. The Bcl-2 apoptotic switch in cancer development and therapy. Oncogene. 2007;26(9):1324-1337.

2. Tsujimoto $Y$, Ikegaki N, Croce CM. Characterization of the protein product of bcl-2, the gene involved in human follicular lymphoma. Oncogene. 1987;2(1):3-7

3. Aukema SM, Siebert R, Schuuring E, et al. Double-hit B-cell lymphomas. Blood. 2011;117(8):2319-2331.

4. Sarkozy C, Traverse-Glehen A, Coiffier B. Double-hit and double-protein-expression lymphomas: aggressive and refractory lymphomas. Lancet Oncol. 2015;16(15):e555e567.

5. Horn H, Ziepert M, Becher C, et al. MYC status in concert with BCL2 and BCL6 expression predicts outcome in diffuse large B-cell lymphoma. Blood. 2013;121(12):22532263.

6. Schuetz JM, Johnson NA, Morin RD, et al. BCL2 mutations in diffuse large B-cell lymphoma. Leukemia. 2012;26(6):1383-1390.

7. Klanova M, Andera L, Brazina J, et al Targeting of BCL2 family proteins with ABT-199 and homoharringtonine reveals BCL2- and MCL1-dependent subgroups of diffuse large B-cell lymphoma. Clin Cancer Res. 2016;22(5):1138-1149.

8. Schmitz R, Wright GW, Huang DW, et al. Genetics and pathogenesis of diffuse large B-cell lymphoma. N Engl J Med. 2018; 378(15):1396-1407

9. Vogler M, Walter HS, Dyer MJS. Targeting anti-apoptotic BCL2 family proteins in haematological malignancies - from pathogenesis to treatment. $\mathrm{Br} \mathrm{J}$ Haematol. 2017;178(3):364-379

10. Davids MS, Roberts AW, Seymour JF, et al. Phase I first-in-human study of venetoclax in patients with relapsed or refractory nonHodgkin Lymphoma. J Clin Oncol. 2017;35(8):826-833.
11. DiNardo CD, Pratz K, Pullarkat V, et al. Venetoclax combined with decitabine or azacitidine in treatment-naive, elderly patients with acute myeloid leukemia. Blood. 2019;133(1):7-17.

12. Anderson MA, Tam C, Lew TE, et al. Clinicopathological features and outcomes of progression of CLL on the BCL2 inhibitor venetoclax. Blood. 2017;129(25):3362-3370.

13. Souers AJ, Leverson JD, Boghaert ER, et al. ABT-199, a potent and selective BCL-2 inhibitor, achieves antitumor activity while sparing platelets. Nat Med 2013;19(2):202208.

14. Leverson JD, Phillips DC, Mitten MJ, et al. Exploiting selective BCL-2 family inhibitors to dissect cell survival dependencies and define improved strategies for cancer therapy. Sci Transl Med. 2015;7(279):279ra240.

15. Kotschy A, Szlavik Z, Murray J, et al. The MCL1 inhibitor S63845 is tolerable and effective in diverse cancer models. Nature. 2016;538(7626):477-482.

16. Moller P, Bruderlein S, Strater J, et al. MedB1, a human tumor cell line derived from a primary mediastinal large B-cell lymphoma. Int J Cancer. 2001;92(3):348-353.

17. Nacheva E, Dyer MJ, Metivier C, et al. B-cell non-Hodgkin's lymphoma cell line (Karpas 1106 ) with complex translocation involving 18q21.3 but lacking BCL2 rearrangement and expression. Blood. 1994;84(10):34223428.

18. Dutta S, Ryan J, Chen TS, Kougentakis C, Letai A, Keating AE. Potent and specific peptide inhibitors of human pro-survival protein Bcl-xL. J Mol Biol. 2015;427(6 Pt B):1241-1253.

19. Ryan J, Letai A. BH3 profiling in whole cells by fluorimeter or FACS. Methods. 2013;61(2):156-164.

20. van Wijk SJL, Fricke F, Herhaus L, et al. Linear ubiquitination of cytosolic Salmonella typhimurium activates NFkappaB and restricts bacterial proliferation. Nat Microbiol. 2017;2:17066.
21. Leverson JD, Zhang $\mathrm{H}$, Chen J, et al. Potent and selective small-molecule MCL-1 inhibitors demonstrate on-target cancer cell killing activity as single agents and in combination with ABT-263 (navitoclax). Cell Death Dis. 2015;6:e1590.

22. Alizadeh $A A$, Eisen $M B$, Davis RE, et al Distinct types of diffuse large B-cell lymphoma identified by gene expression profiling. Nature. 2000;403(6769):503-511.

23. Deng J, Carlson N, Takeyama K, Dal Cin P, Shipp M, Letai A. BH3 profiling identifies three distinct classes of apoptotic blocks to predict response to ABT-737 and conventional chemotherapeutic agents. Cancer Cell. 2007;12(2):171-185.

24. Del Gaizo Moore V, Letai A. BH3 profiling-measuring integrated function of the mitochondrial apoptotic pathway to predict cell fate decisions. Cancer Lett. 2013;332(2):202205.

25. Pham LV, Huang S, Zhang $\mathrm{H}$, et al. Strategic therapeutic targeting to overcome venetoclax resistance in aggressive B-cell lymphomas. Clin Cancer Res. 2018;24(16):39673980.

26. Masir N, Campbell LJ, Jones M, Mason DY. Pseudonegative BCL2 protein expression in a $t(14 ; 18)$ translocation positive lymphoma cell line: a need for an alternative BCL2 antibody. Pathology. 2010;42(3):212-216.

27. Quentmeier H, Drexler HG, Hauer V, et al Diffuse large B cell lymphoma cell line U2946: model for MCL1 inhibitor testing. PLoS One. 2016;11(12):e0167599.

28. Chen L, Willis SN, Wei A, et al. Differential targeting of prosurvival Bcl-2 proteins by their BH3-only ligands allows complementary apoptotic function. Mol Cell. 2005;17 (3):393-403.

29. Willis SN, Chen L, Dewson G, et al Proapoptotic Bak is sequestered by Mcl-1 and $\mathrm{Bcl}-\mathrm{xL}$, but not Bcl-2, until displaced by BH3-only proteins. Genes Develop. 2005;19(11):1294-1305.

30. Westphal D, Kluck RM, Dewson G. 
Building blocks of the apoptotic pore: how Bax and Bak are activated and oligomerize during apoptosis. Cell Death Diff. 2014;21(2):196-205.

31. Liu Y, Mondello P, Erazo T, et al. NOXA genetic amplification or pharmacologic induction primes lymphoma cells to BCL2 inhibitor-induced cell death. Proc Natl Acad Sci U S A. 2018;115(47):12034-12039.

32. Kong W, Zhou M, Li Q, Fan W, Lin H, Wang $\mathrm{R}$. Experimental characterization of the binding affinities between proapoptotic $\mathrm{BH} 3$ peptides and antiapoptotic Bcl-2 proteins. ChemMedChem. 2018;13(17):17631770.

33. Rooswinkel RW, van de Kooij B, de Vries E, et al. Antiapoptotic potency of Bcl-2 proteins primarily relies on their stability, not binding selectivity. Blood. 2014;123(18): 2806-2815.

34. Greaves G, Milani M, Butterworth M, et al. $\mathrm{BH}$-only proteins are dispensable for apoptosis induced by pharmacological inhibition of both MCL-1 and BCL-XL. Cell Death Diff. 2019;26(6):1037-1047

35. Merino D, Whittle JR, Vaillant F, et al. Synergistic action of the MCL-1 inhibitor S63845 with current therapies in preclinical models of triple-negative and HER2-amplified breast cancer. Sci Transl Med. 2017;9(401): eaam7049.

36. Chen HC, Kanai M, Inoue-Yamauchi $A$, et al. An interconnected hierarchical model of cell death regulation by the BCL-2 family. Nat Cell Biol. 2015;17(10):1270-1281.
37. Du H, Wolf J, Schafer B, Moldoveanu T, Chipuk JE, Kuwana T. BH3 domains other than Bim and Bid can directly activate Bax/Bak. J Biol Chem. 2011;286(1):491-501.

38. Vogler M. BCL2A1: the underdog in the BCL2 family. Cell Death Diff. 2012;19(1):6774

39. Adams CM, Mitra R, Gong JZ, Eischen CM. Non-Hodgkin and Hodgkin lymphomas select for overexpression of BCLW. Clin Cancer Res. 2017;23(22):7119-7129.

40. Th'ng KH, Garewal G, Kearney L, et al Establishment and characterization of three new malignant lymphoid cell lines. Int J Cancer. 1987;39(1):89-93.

41. Amini RM, Berglund M, Rosenquist R, et al A novel B-cell line (U-2932) established from a patient with diffuse large B-cell lymphoma following Hodgkin lymphoma. Leuk Lymphoma. 2002;43(11):2179-2189.

42. Tweeddale ME, Lim B, Jamal N, et al. The presence of clonogenic cells in high-grade malignant lymphoma: a prognostic factor. Blood. 1987;69(5):1307-1314.

43. Epstein AL, Levy R, Kim H, Henle W, Henle G, Kaplan HS. Biology of the human malignant lymphomas. IV. Functional characterization of ten diffuse histiocytic lymphoma cell lines. Cancer. 1978;42(5):2379-2391.

44. Kubonishi I, Niiya K, Miyoshi I Establishment of a new human lymphoma line that secretes plasminogen activator. Jpn J Cancer Res. 1985;76(1):12-15.

45. Tohda S, Sato T, Kogoshi H, Fu L, Sakano S, Nara N. Establishment of a novel B-cell lym- phoma cell line with suppressed growth by gamma-secretase inhibitors. Leuk Res. 2006;30(11):1385-1390.

46. Epstein AL, Variakojis D, Berger C, Hecht $\mathrm{BK}$. Use of novel chemical supplements in the establishment of three human malignant lymphoma cell lines (NU-DHL-1, NU-DUL1 , and NU-AMB-1) with chromosome 14 translocations. Int J Cancer. 1985;35(5):619627.

47. Fridberg M, Servin A, Anagnostaki L, et al. Protein expression and cellular localization in two prognostic subgroups of diffuse large B-cell lymphoma: higher expression of ZAP70 and PKC-beta II in the non-germinal center group and poor survival in patients deficient in nuclear PTEN. Leuk Lymphoma. 2007;48(11):2221-2232.

48. Epstein AL, Kaplan HS. Biology of the human malignant lymphomas. I Establishment in continuous cell culture and heterotransplantation of diffuse histiocytic lymphomas. Cancer. 1974;34(6):1851-1872.

49. Abe M, Nozawa $Y$, Wakasa $H$, Ohno $H$ Fukuhara S. Characterization and comparison of two newly established Epstein-Barr virus-negative lymphoma B-cell lines. Surface markers, growth characteristics, cytogenetics, and transplantability. Cancer 1988;61(3):483-490.

50. Gabay C, Ben-Bassat H, Schlesinger M Laskov R. Somatic mutations and intraclonal variations in the rearranged Vkappa genes of B-non-Hodgkin's lymphoma cell lines. Eur J Haematol. 1999;63(3):180-191. 